Article

\title{
Wind-PV-Based Hybrid DC Microgrid (DCMG) Development: An Experimental Investigation and Comparative Economic Analysis
}

\author{
Pervez Hameed Shaikh 1,2,3,* Zohaib Hussain Leghari ${ }^{1,3,4}$, Nayyar Hussain Mirjat ${ }^{1,3}$, \\ Faheemullah Shaikh 1,3, Asif Raza Solangi ${ }^{3}$, Tariqullah Jan ${ }^{5}$ and Muhammad Aslam Uqaili 1,3 \\ 1 Mehran University Center for Energy and Development (MUCED), Mehran University of Engineering and \\ Technology, Jamshoro 76062, Pakistan; zohaib.leghari@faculty.muet.edu.pk (Z.H.L.); \\ nayyar.hussain@faculty.muet.edu.pk (N.H.M.); engrfaheemshaikh@gmail.com (F.S.); \\ aslam.uqaili@faculty.muet.edu.pk (M.A.U.) \\ 2 Office of Research, Innovation and Commercialization (ORIC), Mehran University of Engineering and \\ Technology, Jamshoro 76062, Pakistan \\ 3 Department of Electrical Engineering, Mehran University of Engineering and Technology, Jamshoro 76062, \\ Pakistan; Pakistan; solangiasif66@gmail.com \\ 4 Center of Electrical Energy Systems (CEES), University Technology Malaysia (UTM), 81310 Skudai, \\ Johor, Malaysia \\ 5 Department of Electrical Engineering, University of Engineering and Technology, Peshawar 25120, Pakistan; \\ tariqullahjan@uetpeshawar.edu.pk \\ * Correspondence: pervez.hameed@faculty.muet.edu.pk; Tel.: +92-22-277-1197
}

Received: 10 April 2018; Accepted: 10 May 2018; Published: 18 May 2018

check for updates

\begin{abstract}
The cyclical nature and high investment costs of the wind and photovoltaic renewable energy sources are the two critical issues seeking attention for the use of such systems in backup or isolated applications. This paper aims to present the experimental and economic analysis of a wind-photovoltaic-based hybrid direct current microgrid (DCMG) system for backup power and off-grid isolated power generation system for emergency purposes. The two distributed generating units comprising photovoltaic panels and wind generator were designed and developed for the experimental study. A lead-acid battery is also added as an energy storage system to enhance the system supply. The electric load of this system comprise of 42 DC light emitting diode (LED) lamps of 12 Watt each and a 25 Watt DC fan. The charge controller provides the control and protection features for the designed system. The complete system design and fabrication of this system have been undertaken at Mehran University of Engineering \& Technology (MUET, Jamshoro, Pakistan). The compatibility of the designed system has been analysed by comparing the Levelized Cost of Energy (LCOE) with a conventional gasoline generator system of the same capacity. The capital, running and lifetime costs of DCMG are found to be 1.29, 0.15 and 0.29 times those of the gasoline generator, respectively. Moreover, it is found that per unit cost of gasoline generator is $\$ 0.3$ (i.e., PKR 31.4) which is almost 3.4 times higher than that of the hybrid DCMG system. The performance and cost evaluation of the designed system indicate its broad potential to be adopted for commercialisation to meet backup power and off-grid power requirements. This study concludes that proposed DCMG system is a not only low cost, but also a pollution-free alternative option compared to the existing traditional small gasoline generator system.
\end{abstract}

Keywords: DC microgrid; hybrid system; renewable energy; cost of energy 


\section{Introduction}

In developing countries, a larger number of the population has no access to electricity, adversely affecting their socio-economic growth. One of the critical reasons for the scarcity of electricity in this larger population is their lack of access to the national electric grid [1]. Pakistan, being a developing country, is also facing a similar dilemma. About $30 \%$ of the country's population has no access to electricity [2]. The situation is worse in rural areas, where $44 \%$ of the households, comprising more than 40,000 villages, are not connected to the national grid [3]. The dispersed population and varied topography are the primary hurdles to the grid expansion requiring a considerable amount of investment for spreading the transmission and distribution infrastructure $[4,5]$. To overcome this situation, installation of stand-alone power generation systems is regarded as the most suitable and acceptable solution to electrify the off-grid areas to supporting the local socio-economic activities. Conventionally, standalone gasoline generating units are used to electrify off-grid areas. However, due to volatile fuel prices, high operation and maintenance costs as well as the emissions from such power generation systems, they are considered unsustainable options.

Fortunately, Pakistan has great potential of renewable energy resources such as solar, wind, biomass and hydropower. A summary of the renewable energy potential of these resources of the country is presented in Table 1 [6]. The renewable energy sources are not only sustainable but at the same time ensure long drawn energy supply sources which are locally available. These resources can reduce the country's reliance on the imported fuel. Also, the renewable energy-based stand-alone off-grid systems offer the technical solution to electrify the rural and semi-urban areas of the country which can be operated in both grid- and off-grid modes. In Pakistan, electricity generation mainly relays on fossil fuels, with an overall share of $64.3 \%$ which breaks down to $35.2 \%, 29 \%$ and $0.1 \%$ shares for oil, gas and coal, respectively [7]. The renewable energy potential of Pakistan is poorly explored, with a negligible share of the same in the power generation. Table 2 presents the electrical power generation energy mix scenario of Pakistan for the year 2014 [8].

Table 1. Renewable energy potential in Pakistan [9-16].

\begin{tabular}{|c|c|}
\hline Parameter & Characteristics \\
\hline \multicolumn{2}{|l|}{ Solar } \\
\hline Solar global insulation & $5-7 \mathrm{kWh} / \mathrm{m}^{2} /$ day \\
\hline Available average solar energy & $5.5 \mathrm{kWh} / \mathrm{m}^{2} /$ day \\
\hline Mean sunshine duration & $\begin{array}{l}\text { 8-10 h/day } \\
300 \text { days/year }\end{array}$ \\
\hline Global solar irradiance & $\begin{array}{l}1500-3000 \mathrm{~h} / \text { year } \\
200-250 \mathrm{~W} / \mathrm{m}^{2} / \text { day } \\
6840-8280 \mathrm{MJ} / \mathrm{m}^{2} / \text { year } \\
1.9-2.3 \mathrm{MWh} / \mathrm{m}^{2} / \text { year }\end{array}$ \\
\hline Total solar energy potential exists in Pakistan & 2.9 Million MW \\
\hline \multicolumn{2}{|l|}{ Wind } \\
\hline Wind speeds in Sindh \& Balochistan's coastal areas (10 m height) & $4-9 \mathrm{~m} / \mathrm{s}$ \\
\hline Wind speeds in Sindh \& Balochistan's coastal areas (50 m height) & $12.5 \mathrm{~m} / \mathrm{s}$ \\
\hline Total wind power potential of coastal areas of Sindh & $43,871 \mathrm{MW}$ \\
\hline Viable wind power potential of coastal areas of Sindh & $11,000 \mathrm{MW}$ \\
\hline Total wind power potential of Pakistan & $346,000 \mathrm{MW}$ \\
\hline Viable wind power potential of Pakistan & $120,000 \mathrm{MW}$ \\
\hline \multicolumn{2}{|l|}{ Hydropower } \\
\hline Hydropower potential of Pakistan & 30,000-50,000 MW \\
\hline
\end{tabular}


Table 1. Cont.

\begin{tabular}{|c|c|}
\hline \multicolumn{2}{|l|}{ Biomass } \\
\hline Potential of sugarcane trash for power generation (2011-2012) & $20,313 \mathrm{GWh}$ \\
\hline Potential of cotton sticks for power generation (2011-2012) & $8671 \mathrm{GWh}$ \\
\hline Potential of maize stalks for power generation (2011-2012) & $4627 \mathrm{GWh}$ \\
\hline Potential of paddy straw for power generation (2011-2012) & $15,058 \mathrm{GWh}$ \\
\hline \multicolumn{2}{|l|}{ Biogas } \\
\hline Total animal (cow + buffalo) population (2011-2012) & 70 Millions \\
\hline Manure produced per year at $10 \mathrm{~kg} /$ day/animal (2011-2012) & 255.5 Million Tons \\
\hline Collected manure produced per year (2011-2012) & 127.750 Million Tons \\
\hline Biogas produced at $50 \mathrm{~m}^{3} /$ ton manure (2011-2012) & 6387.5 Million $\mathrm{m}^{3}$ \\
\hline Thermal energy in biogas at $22 \mathrm{MJ} / \mathrm{m}^{3}$ & 140.525 Million GJ \\
\hline Total biogas power potential at $8.14 \mathrm{kWh} / \mathrm{m}^{3}$ & $13,670 \mathrm{GWh}$ \\
\hline
\end{tabular}

The key hurdles pertaining to the adoption of inexhaustible renewable resources are primarily their volatile nature and high investment costs. The output of photovoltaic (PV)-based power generation is dependent on the solar irradiance during sunshine hours of the day only mismatching a large part of the electricity demand. Similarly, the output of wind-based power generation is dependent on fluctuating wind speed. This leads to the oversized and cost-intensive PV and wind generator (WG) systems to attain the reliability goal. Therefore, Hybrid Renewable Energy Systems (HRES) are considered reliable and cost-effective solutions to address the deficiencies of single source based renewable energy systems [9].

Table 2. Energy mix scenario in Pakistan [7].

\begin{tabular}{ccc}
\hline Source & Total Power Generation (\%) & Electricity Generation (MW) \\
\hline Oil & 35.2 & 8025 \\
Gas & 29 & 6611 \\
Coal & 0.1 & 23 \\
Hydel & 29.9 & 6816 \\
Nuclear & 5.8 & 1322 \\
\hline Total & 100 & 22,797 \\
\hline
\end{tabular}

The HRES is a system which is based on more than one type of distributed generator (DG). The comparison of key cost parameters of the conventional and renewable energy system reveal that installation cost of the conventional energy system is less, but the operating and maintenance costs of renewable energy systems are quite low. Consequently, renewable sources offer reduced lifetime costs compared to conventional energy systems. As such, HRESs are a viable option for power generation in isolated locations which can be further optimised through various design configurations. A number of studies have been conducted to explore possibilities of wind-PV based hybrid power generation systems. These studies have evaluated the various parameters of hybrid wind-PV systems, including their performance, economic parameters, optimal wind-PV unit size, converter and controller designs, as well as reliability.

Manoj et al. [17] have analyzed the economic parameters of PV and hybrid wind-PV systems with respect to the transition from conventional to hybrid wind/solar power supply of households and commercial buildings. Abbas and Hassan [18] have estimated the Levelized Cost of Energy (LCOE) of a hybrid wind-PV-diesel power generation system using HOMER software. They concluded that combining the wind-PV system with diesel power generation system can considerably reduce the overall LCOE. The hybrid wind-PV-battery performance evaluation of the installed system in the Adrar province of southwestern Algeria was studied by Maouedj et al. [19]. They concluded that power 
supplied were $84 \%$, and $16 \%$ from the PV system and wind turbine, respectively. The hourly-mean battery state-of-charge (SOC) varied between a maximum of $74 \%$ and a minimum of $56 \%$.

In another study [20] a dynamic component model and the simulation model for a hybrid energy system was developed using MATLAB/Simulink. The overall power management strategy for coordinating the power flows among the different energy sources was presented in this research. Vivek and Bhatia [21] analyzed a hybrid solar and wind power generation system for domestic application at low wind speeds in the Northern areas of India. For this system, $100 \mathrm{~W}$ solar penal and a turbine made of a permanent magnet DC motor of rating 90 volts, 3.9 Amp and 2500 revolutions per minute (RPM) was used. The study concluded that the proposed system is suitable for domestic use where wind speeds are comparatively low. A small-scale energy system called emergency container consisting of a hybrid PV/wind/engine energy system was also developed by Sigarchian et al. [22]. The system was modelled with TRNSYS and its operation during one year analysed for two geographical locations (Nairobi, Kenya and Nyala, Sudan) with relatively high solar insolation. The power generated and shared by the solar and wind energy in Nairobi was $63 \%$ and $27 \%$ and in Nyala it was $80 \%$ and $12 \%$ respectively. Godson et al. [23] have also proposed a solar PV-wind-based hybrid power generation system. The proposed system mainly relied on the microcontroller and ensured the optimum utilization of resources and hence improved the efficiency compared to the stand-alone solar or wind generating systems. Another study [24], has proposed a relay-based controller design for hybrid power systems. The structure of the proposed DC bus bar system carries the photovoltaic power, wind turbine's and grid's rectified power. The DC load can be directly connected to the DC bus bar while the AC load feeds electric devices. The working voltage of the designed system was fixed to $12 \mathrm{~V}$ DC. Wang [25] has designed a hardware and a software-based PV charging controller and wind charging controller in a prototype development study. The primary circuit uses a buck-boost converter that allows the system to work in boost state under breeze conditions and work in the depressurised state under strong wind conditions, hence improving the overall efficiency of the system. Diab et al. [26] have analyzed a hybrid PV/wind/diesel/battery system and concluded that the proposed system is practical and offers a cost-effective solution to satisfy the electrical energy needs for an environment-friendly factory located in New Borg El Arab city, Egypt. In this study, the simulation was undertaken using HOMER software considering the following system specifications: PV arrays of $60 \mathrm{~kW}$, WT of $100 \mathrm{~kW}$, diesel generator of $40 \mathrm{~kW}$, power converters of the rating of $50 \mathrm{~kW}$ and 600 batteries with the capacity of $589 \mathrm{Ah}$. In another study, Freire et al. [27] have developed a small-scale prototype of PV-wind hybrid system, with batteries for energy storage. The power output from DGS of this system was connected to the common DC-Bus through the power converters and various experiments were performed on the system under both steady state and transient conditions to analyse the system performance. Moreover, an experimental setup of solar and wind hybrid system has been designed in [28] and has interfaced to the grid system. Jadallah et al. [29] have simulated and analysed a small scale stand-alone PV-wind hybrid power system. The wind turbine and PV module were modelled considering specific parameters of the individual system. MATLAB was used to solve the mathematical model for the designed system. The results of the study showed that the load was consuming the power from both the sources but due to variations in conditions (i.e., solar radiation and wind speed), there was alternatively an excess and lack of power supply.

A microgrid with wind and PV resources was also proposed by Sungwoo and Kwasinski [30]. In order to combine these PV and wind energy sources, an MI Ćuk converter or a multiple-input Single Ended Primary Inductor Converter (MI SEPIC) with a DC bus system was used since Current-Source-Interface Multiple-Input Converter (CSI MIC) is more efficient for input current control and Maximum Power Point Tracking (MPPT) in PV modules. MICs were chosen as they provide a cost-effective and flexible method to interface various renewable energy sources [31]. The voltage level of $380 \mathrm{~V}$ was considered because it is more suitable for bidirectional power flow between the proposed power system and utility grid [32]. The Energy Storage System (ESS) was connected 
to support the power production and maintain power supply in the islanded mode. The model and simulation of the Hybrid Electric Power System (HEPS) of a solar tracking PV array and wind interfaced to the grid using MATLAB/SIMULINK. A DC/AC converter and control circuit was designed, and results were analysed. It was concluded that the total harmonic distortion at the local bus was within the tolerable perimeters. Rashid et al. [33] have reviewed the various challenges and opportunities/solutions pertaining hybrid solar PV and wind energy systems. More specifically, the challenges and opportunities concerning stand-alone solar PV and wind hybrid systems have been discussed. As such, a study discussing the advantages of the inclusion of a DC interface bus for the coupling mentioned that it does not require to maintain frequency and synchronism [33]. Further, the output voltage from all the sources was set to be fixed, and output current from each source was controlled independently. The battery bank acts as a voltage source to control the common DC bus voltage by charging (in case of extra power) or discharging the battery (in case of shortage of power).

An energy management solution for optimum power flow and economic control for microgrid has also been proposed by Ganesan et al. [34]. The system consists of a centralized control with various local controllers which enables the precise management of power flow attained with the use of a forecasting model to predict the power availability from renewable sources, battery backup, and supplying power to loads with efficient and economical operation. The mathematical model for coordination of photovoltaics, storage battery and load demand has been considered in another study by Cucchiella et al. [35]. Discounted cash flow analysis, net present value and break-even analysis are undertaken in this study, which reveals that the proposed system would be profitable only when subsidies were provided for the purchase of various pieces of equipment. Javaid et al. [36] have proposed a genetic wind-driven algorithm for a demand-side management controller for residential consumers. The study considered effective flattening of the load to schedule the demand of single or multiple homes. This paper compares various heuristic techniques for load profile management and found the effectiveness of hybrid genetic wind driven algorithm. Dali et al. [37] have investigated the operation of a grid-connected PV-wind system using a standalone inverter. The simulation and experimental analysis reveal that the proposed inverter is both capable of working in grid-connected and in standalone mode in a micro-grid generation setup. The photovoltaic, fuel cell and wind hybrid generation system in a stand-alone generation for maximum power extraction was also studied by Ou and Hong [38]. This stand-alone hybrid generation microgrid system was developed using MATLAB/Simulink for the performance testing and effective power-sharing analysis. Hong et al. [39], proposed grid-connected hybrid PV/wind system to extract the maximum power along with a diesel generator to balance power supply and simulated the same. The power output was controlled in the hybrid system with diesel generation and was found capable of frequency control despite varying load conditions. Bui [40] developed an auto-configuration function to integrate old and new devices (microgrids) with rescheduling process. This system assists energy management system to reduce operational cost and alleviate load shedding. Ou [41] also proposed a microgrid with photovoltaic, wind, microturbine and battery. The power flow network configuration through optimized and stochastic (evolutionary programming) searching algorithm has been implemented. Lin and Ou [42] studied an unbalanced distribution of three phase fault analysis of the hybrid system. The topological characteristics were analyzed and found to be robust, accurate and speedy computations. The system is capable of handling three-phase faults under predefined matrices of the distribution network. Chen [43] designed a protection scheme of stage fault test for a $380 \mathrm{~V}$ microgrid. The zero-sequence voltage magnitude was kept for the detecting the variable of the ground fault condition. The faulty zone was detected with directional overcurrent scheme. Ou [44] proposed an algorithm for microgrid distribution ground fault. The developed algorithm possess topological characteristics and can be used to solve a different network type. Ou [45] has also developed a method for hybrid compensation for the microgrid to analyze unsymmetrical faults for the three-phase model. This method is capable of solving different types of single and simultaneous unsymmetrical faults. Eltamaly, and Al-Shamma'a [46] 
have introduced an optimal autonomous renewable configuration for sizing, penetration and cost computations. In this study, the simulation and design of hybrid PV, wind-diesel and battery system was undertaken and assessed for three-phase configurations. Türkay and Telli [47] have presented a techno-economic perspective for micro-power optimization program. The hydrogen power with renewable energy sources were evaluated for the technology selection, optimal power, operation strategy along with standalone and grid-connected structure with an economical perspective.

The findings of the extensive literature presented above highlight various significant challenges which include the voltage regulation, protection against power backflow towards sources and loads. Also, several studies conducted were based on complex electronic circuitry and costlier due to the transformation of ac power into DC output. The recent improvement and advances in semiconductor technology, especially in the field of power electronic converters has encouraged the researchers and engineers to rethink of DC transmission and distribution systems. This development is significant to serve the current power system with increased overall efficiency hence facilitating the electricity access in remote areas. Besides various other valid reasons, there has been the availability of different DC operated sources and loads in local markets. Few of these countable sources are solar PV, fuel cells and storage devices such as a battery. This study is, therefore, based on the experimental setup of wind-photovoltaic hybrid DC microgrid (DCMG), designed and fabricated locally, and aims to provide economic and comparative analysis of the developed system with respect to a conventional gasoline generator performance. This comparative analysis supports the installation of hybrid DCMG as compared with the gasoline technology is an advancement of our own work [48]. Moreover, the performance and cost evaluation of the designed system portrays its broad potential to be adopted for the commercialization at off-grid locations. The designed system is not only low cost but also a pollution-free alternative option compared to the traditional small gasoline generator system.

The following sections of this study are organised as follows: Section 2 presents a detailed description of the materials and methods of this study, including the experimental setup. Section 3 provides the results and relevant analysis of the designed system. The Levelized Cost of Energy (LCOE) analysis of the designed hybrid DCMG system and a conventional gasoline generator system are presented in Section 4. Finally, the conclusions and recommendations of this study are drawn in Section 5 of the paper.

\section{Material and Methods}

A prototype of the designed system is set at the coordinates $25.4084^{\circ} \mathrm{N}, 68.2605^{\circ} \mathrm{E}$ on the roof of the old administration block of the Mehran University of Engineering \& Technology (MUET, Jamshoro, Pakistan) as shown in Figure 1. The electrical energy output of PV panels and WG are dependent on the solar irradiation and wind speed, respectively. The required solar irradiance data was collected from online solar maps which were produced by the Alternate Energy \& Development Board (AEDB, Pakistan) in collaboration with World Bank in March 2017 [49]. Wind speed data has also been collected from AEDB. The data collected shows that the selected site has an average Global Tilted Irradiation (GTI) of $2250 \mathrm{kWh} / \mathrm{m}^{2} /$ day with Direct Normal Irradiation (DNI) of $1685 \mathrm{kWh} / \mathrm{m}^{2} /$ day. It is also figured out that the Jamshoro region has an annual average wind speed of $8.5 \mathrm{~m} / \mathrm{s}$ at $50 \mathrm{~m}$ height with a wind power density of $770 \mathrm{~W} / \mathrm{m}^{2}$ [49].

The designed hybrid DC microgrid (DCMG) system is comprised of photovoltaic (PV) panels, a wind generator (WG) system, a battery-based energy storage system (BESS), charge controllers (CCs), LED lights and fan-based DC load. Figure 2 shows the schematic flow diagram for the sources, battery backup and loads of the designed system. The PV panels and WG systems are connected in parallel with each other and with the BESS via CCs.

The PV system comprises of three panels of monocrystalline structure, each rated as $150 \mathrm{Wp}$ with total $450 \mathrm{Wp}$ of capacity at Standard Testing Conditions (STC). The STC of the employed PV panels are irradiance $=1000 \mathrm{~W} / \mathrm{m}^{2}$; operating temperature of cell $=25^{\circ} \mathrm{C}$ and air mass $(\mathrm{AM})=1.5$. The PV panels 
cover an area of $3.0192 \mathrm{~m}^{2}$. The WG system is rated as $24 \mathrm{~V} ; 50 \mathrm{Wp}$. BESS is based on one lead-acid battery of $12 \mathrm{~V}, 50$ Ah capacity.

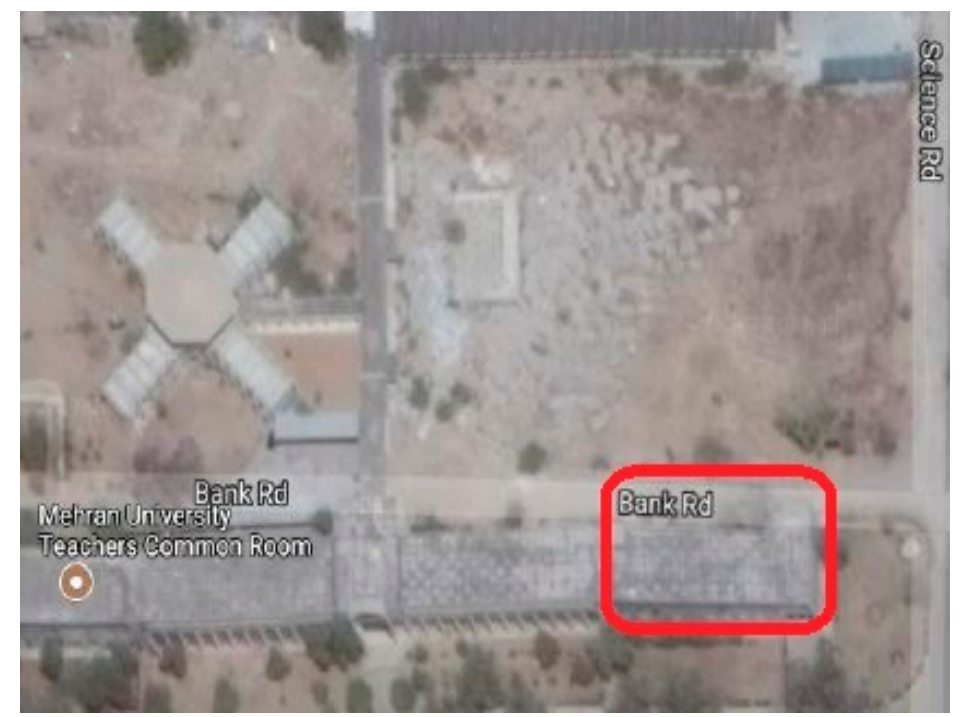

Figure 1. Aerial Coordinates of the DC microgrid location at MUET (Jamshoro, Pakistan).

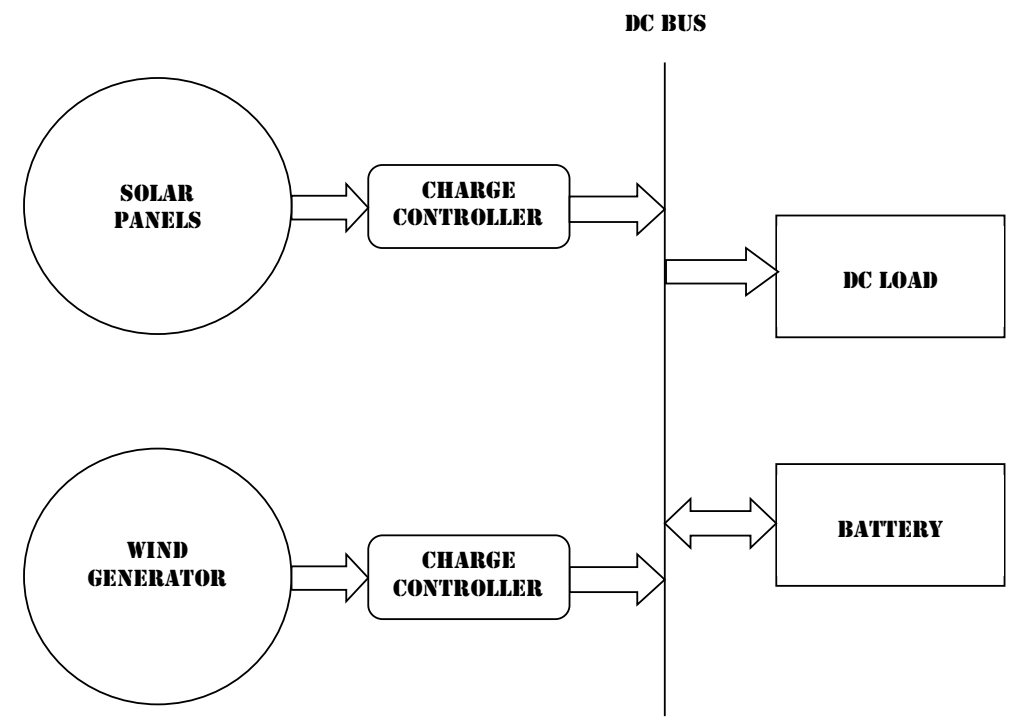

Figure 2. Schematic flow diagram of the integrated DC microgrid system.

The generated power of the Distributed Generating (DG) units, i.e., PV and WG systems, is supplied to the DC load which comprises 40 LED bulbs of $12 \mathrm{~V}, 12 \mathrm{Wp}$ and 1 fan of $12 \mathrm{~V}, 25 \mathrm{Wp}$. Table 3 presents the specifications of the solar $\mathrm{PV}$, wind generator ratings and loads connected with the proposed DC microgrid.

The installation of power generating units of any size, type and at location requires undertaking a feasibility analysis with respect to the effectiveness, practicability and technological competitiveness of the proposed power units. Table 1 of this paper duly portrayed the enormous renewable energy potential of Pakistan to install WG- and PV-based HRES systems for grid connected or isolated facilities. An important aspect which carries high significance regarding the installation of any power generation unit is the type of load to which electricity would be supplied. In this context, an experimental study of the load connected with the wind-PV based HRES was undertaken. The total kWh generated were 
supplied to the designed electrical load throughout the day, and relevant data was collected and analyzed. Furthermore, the performance and economic analysis of the system has been carried out by considering the generated energy of this system for its lifetime including both capital and running costs of the proposed HRES system.

Table 3. DC microgrid sources, loads and battery backup specifications.

\begin{tabular}{cc}
\hline \multicolumn{2}{c}{ PV Panels } \\
\hline Rated power per panel & $150 \mathrm{~W}$ \\
Total power of the three panels & $450 \mathrm{~W}$ \\
Rated voltage per panel & $18 \mathrm{~V}$ \\
Rated current per panel & $8.96 \mathrm{~A}$ \\
Open circuit voltage & $21.6 \mathrm{~V}$ \\
Short circuit current & $9.0 \mathrm{~A}$ \\
Number of cells per panel & 36 \\
Size (mm $\times$ mm $\times$ mm) & $1480 \times 680 \times 40$ \\
\hline WG System & \\
\hline Rated power & $50 \mathrm{~W}$ \\
Rated voltage & $24 \mathrm{~V}$ \\
Binimum operating wind speed & $2 \mathrm{~m} / \mathrm{s}$ \\
Rated operating wind speed & $6-8 \mathrm{~m} / \mathrm{s}$ \\
\hline BESS \\
\hline Rated voltage \\
Ampere-hour rating & $12 \mathrm{~V}$ \\
DC Load & $50 \mathrm{Ah}$ \\
\hline PED bulbs & - \\
Power rating & $12 \mathrm{~W}$ \\
Voltage rating & $12 \mathrm{~V}$ \\
Number of bulbs & 40 \\
\hline Noltage rating & - \\
\hline
\end{tabular}

The photovoltaic panels and wind generator generate power, and the charge controllers will control the flow of power towards the load and battery backup. Based on the state of charge of the battery, the charge controller decides and shares the energy flow between the battery and load. If the battery is fully discharged, the available power will be supplied to it. Moreover, when the battery is partially charged, the power supply is being shared with the battery and to the load. During the times when the battery is fully charged, the entire available energy from DG units feed the load. If there is no or partial availability of power from DG sources, the charged battery will contribute to the load's energy requirement by feeding its stored energy. Hence, for the designed system, fulfilling the battery's energy need is set as the priority and the additional power than its demand will be send to the load. This is because the opposite order may not leave sufficient energy as per the battery demand and failure to do so will not leave any backup energy source for the load. The flow chart shown in Figure 3 depicts the operational flow diagram of the designed hybrid DCMG system. In the following section, the result and analysis pertaining operation of hybrid DC microgrid operation are presented in detail. 


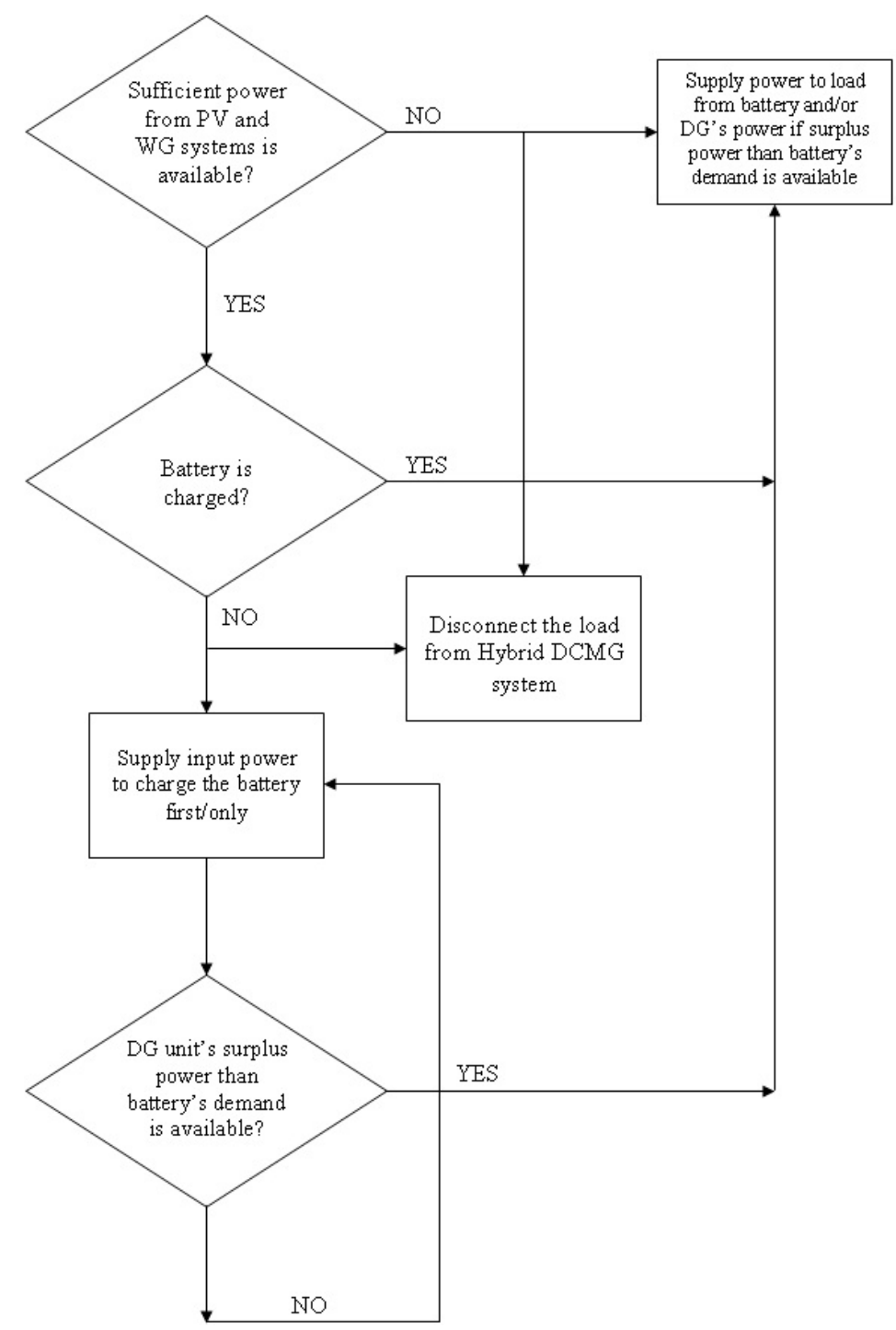

Figure 3. Flowchart that describes the operation of designed hybrid DC microgrid (DCMG) system.

\section{Results and Analysis: Hybrid DC Microgrid Operation}

\subsection{Photovoltaic (PV) Characteristics}

The energy extracted from the PV system is proportional to the solar sunshine. During an average 8-10 sunshine hours in a day, the PV system contributes its energy input to HRES. The comparative rating of PV system to that of WG system make the PV system as a primary source of energy for the designated load. Hence, in the daytime, a significant part of the load relies on the PV energy feed. Figure $4 \mathrm{a}$,b respectively show the solar irradiance pattern and generated PV power on 30 March 2017 for the location of the experimental setup. This illustrates the dependence and proportionality of PV power output on solar irradiance level. It is evident that both the solar irradiance and PV power output peaks occurred at the same time, i.e., from 10:00 to 14:00 $\mathrm{h}$ of the day. The generated PV power was utilised to supply the load and to charge the battery simultaneously. For the time of day when the sunshine dropped, the output of the solar PV power also dropped. Thus after 16:00 h, it was observed that the overall output of PV system had dropped considerably. The average total energy generated by PV system was estimated to $1.73 \mathrm{kWh}$ per day. 


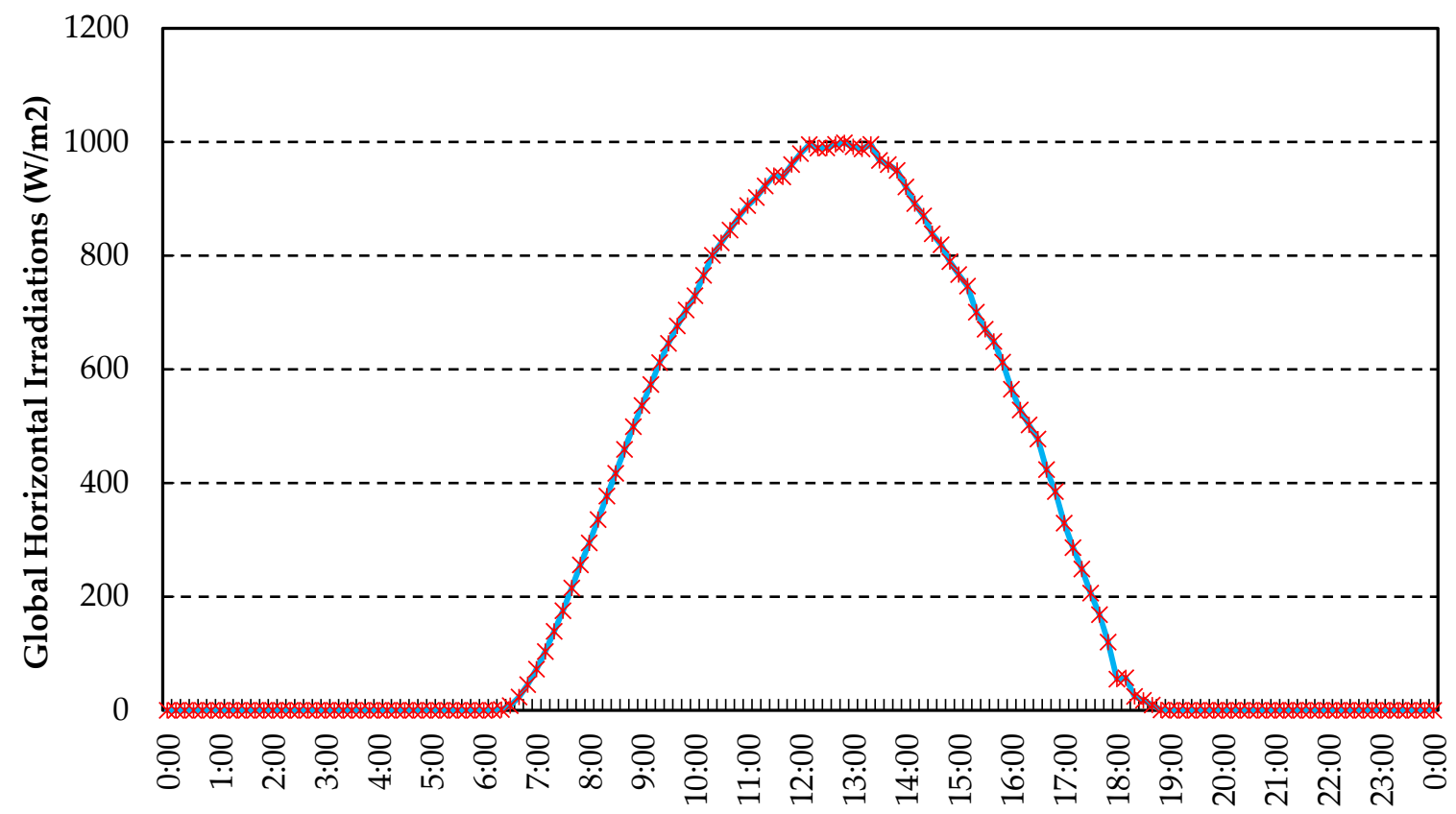

Hours

(a)

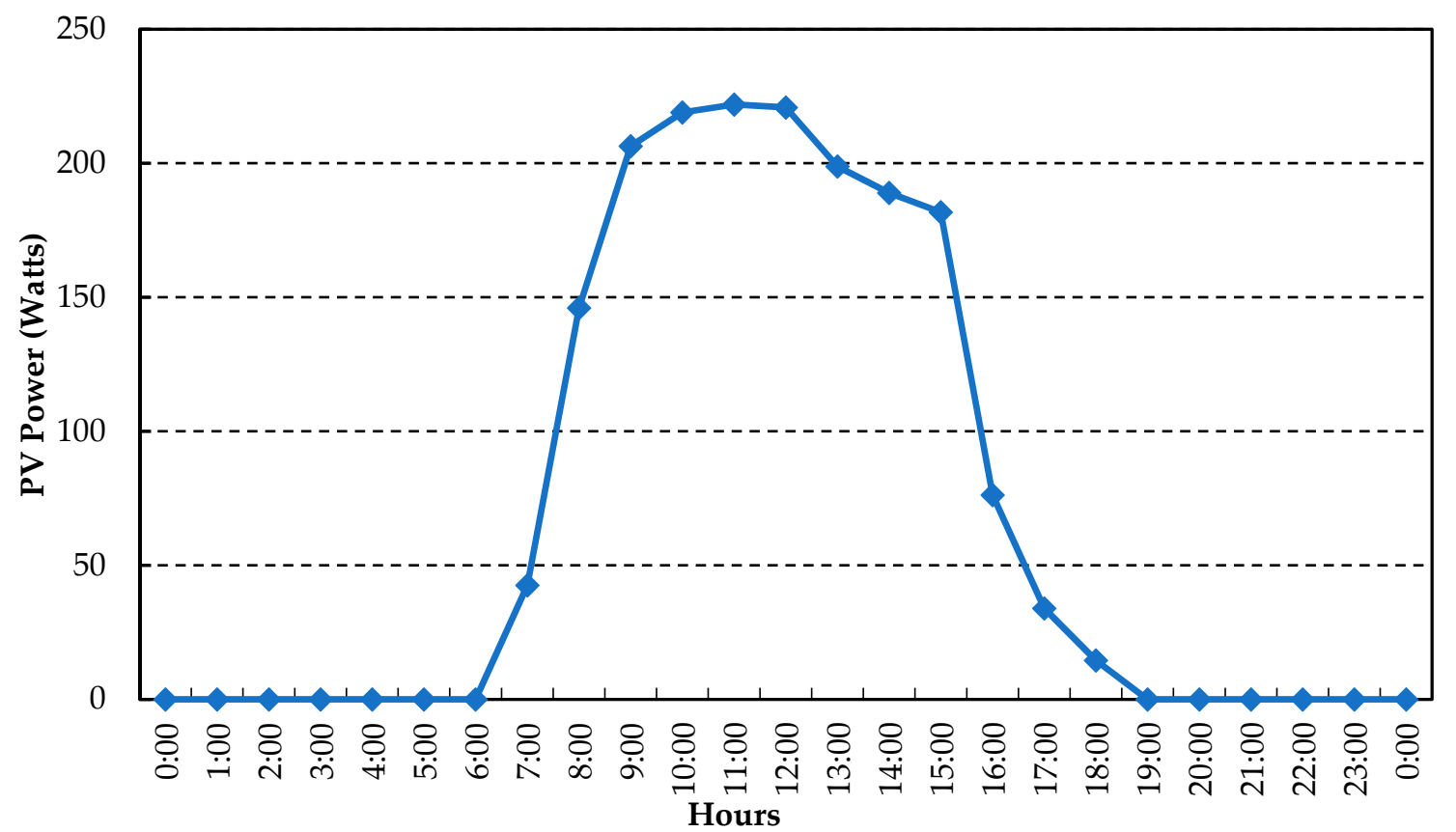

(b)

Figure 4. The solar irradiance pattern and generated PV power on 30 March 2017. (a) Solar irradiance $\left(\mathrm{W} / \mathrm{m}^{2}\right)$ and (b) PV power output (Watts).

\subsection{Wind Generator (WG) Characteristics}

In the designed hybrid DCMG system, the WG rating was considerably smaller than that of the PV system. Unlike the PV system, it can supply power throughout the day if enough wind speeds are available. Figure 5 shows the wind speed statistics and generated power output of the WG system observed on 30 March 2017. 


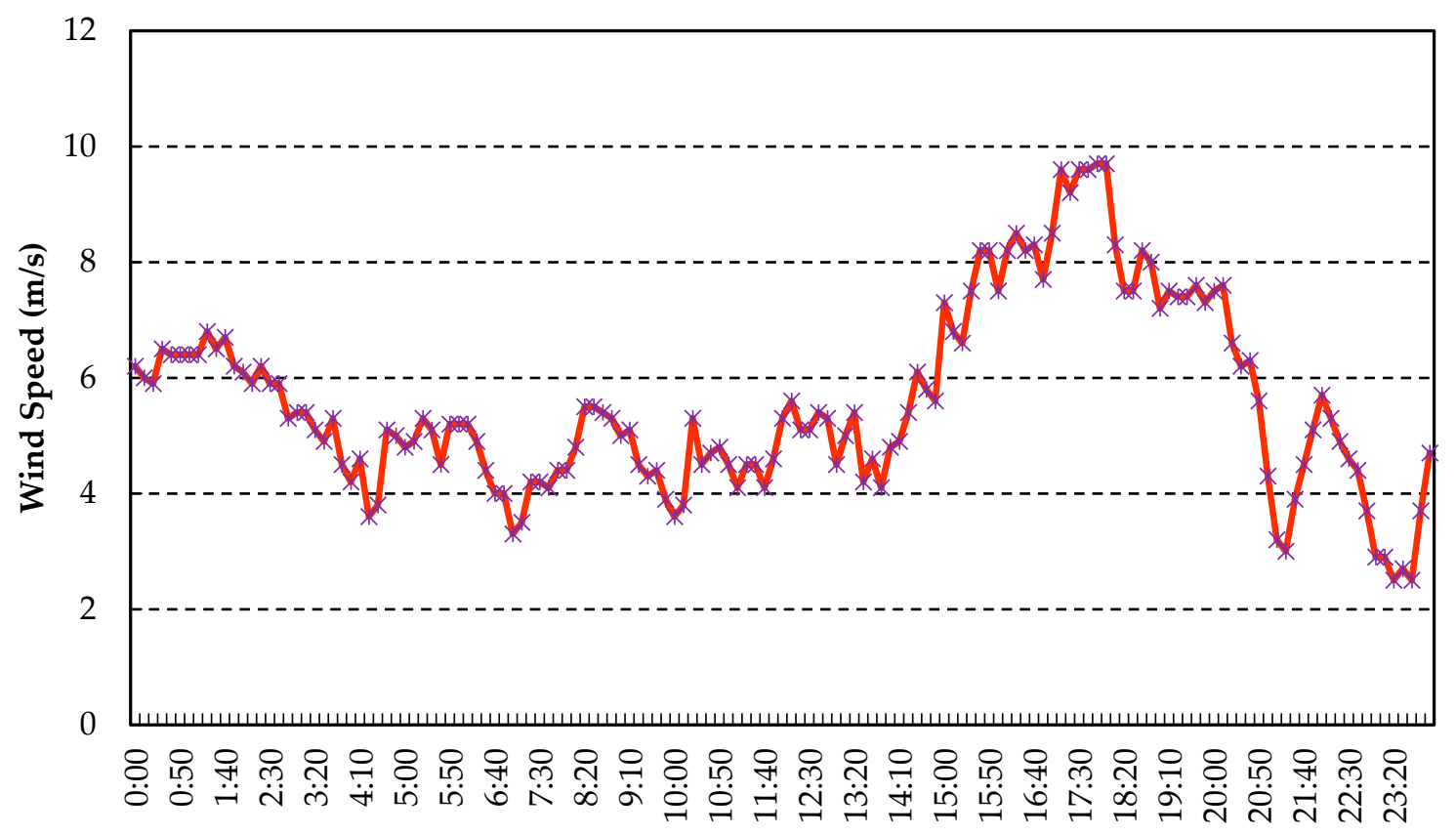

Hours

(a)

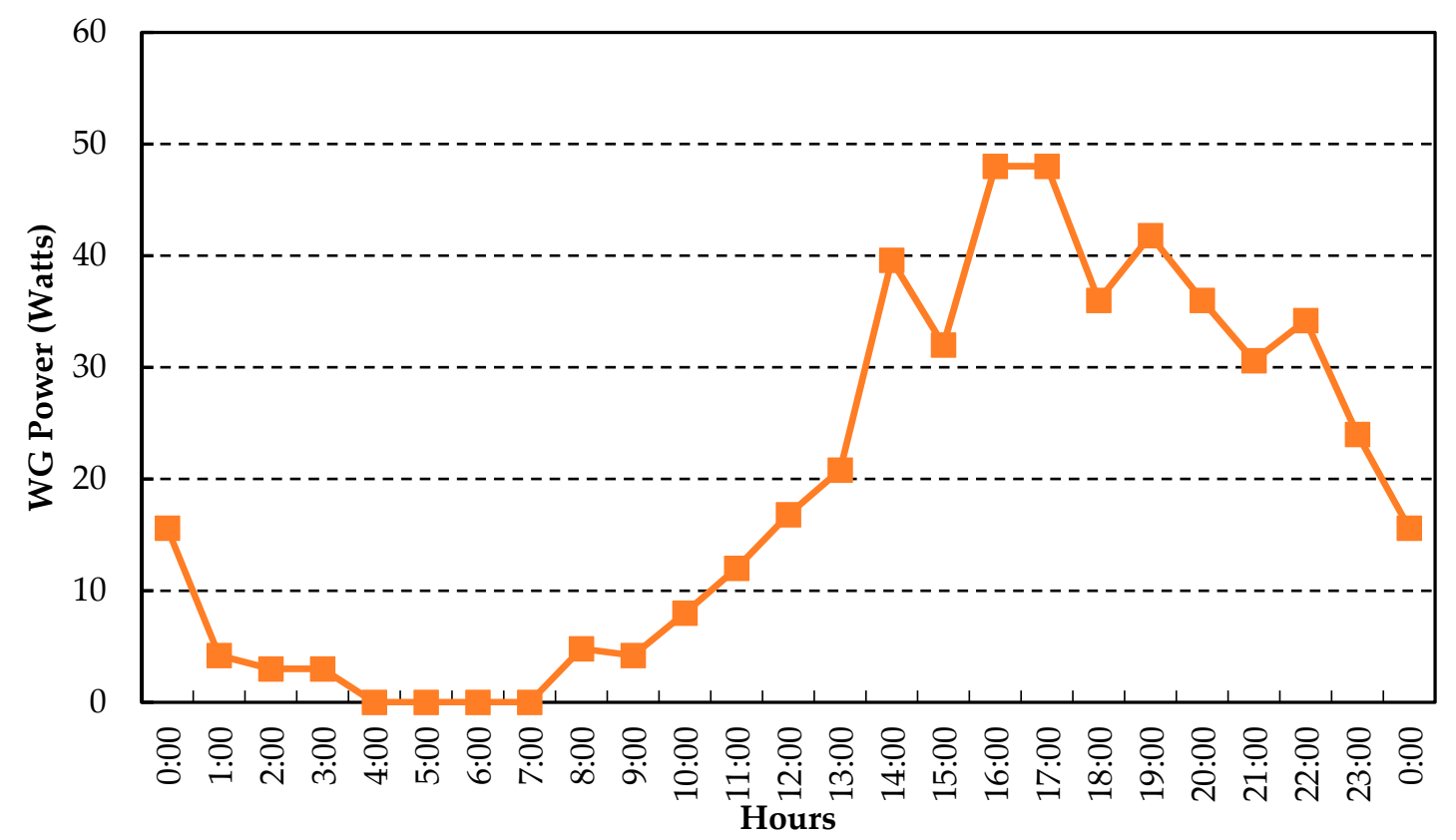

(b)

Figure 5. The wind speed statistics and generated power output of the WG system on 30 March 2017. (a) Wind speed (m/s) and (b) WG power output (Watts).

Though the WG's power output is proportional to the wind speed, however, another factor which mainly affects the WG performance is the wind direction. Since the alignment of the designed WG system is fixed, as such, it is seen at various points of the graph that at lower wind speeds the WG system produces a large power output compared to the time when higher wind speeds are available. It is because the wind directions were in the line of sight of the WG system, as such, more power was generated. Moreover, the generated WG power data is collected manually from throughout the day. 


\subsection{Battery Characteristics}

It can be observed from Figures 3 and 4 that power output of the PV and WG systems is unsustainable due to their intermittent power generation capabilities. For this reason, a lead-acid battery was added to increase the overall reliability of the hybrid wind-PV system. This Battery-Based Energy Storage System (BESS) is the only component of the designed system which works in both supply (as source) and consumption (as load) modes. For the times when enough energy supply from PV and WG systems is sufficient, the battery consumes the available power to get charged. The surplus power which is in excess to that of the battery's charging demand will be supplied to the load. Figure 6 shows that for the time between 08:00-16:00 $\mathrm{h}$ of the day, the battery consumes the power supplied by both DGs, especially PV system supplies enough power to meet the load demand and to charge the battery. During this time the battery's graph follows the negative path, i.e., below the reference line, as it acts as a load during the daytime interval. However, after 16:00 h, the battery supplies its stored energy to the load as there is a significant decrease in the DGs power output. Further, following sunset, WG system will be the only means which can charge the battery if sufficient wind speed is available. Thus, at 16:00 $\mathrm{h}$ and later, battery follow the positive path as it acts as a source during this time. With a continuous power supply of $5 \mathrm{~h}$, at around 21:00 h, the charge controller would be disconnected from HRES. After that, from 21:00 to 07:00 h the battery will be charged by WG system only, which is also subject to the availability of sufficient wind speeds.

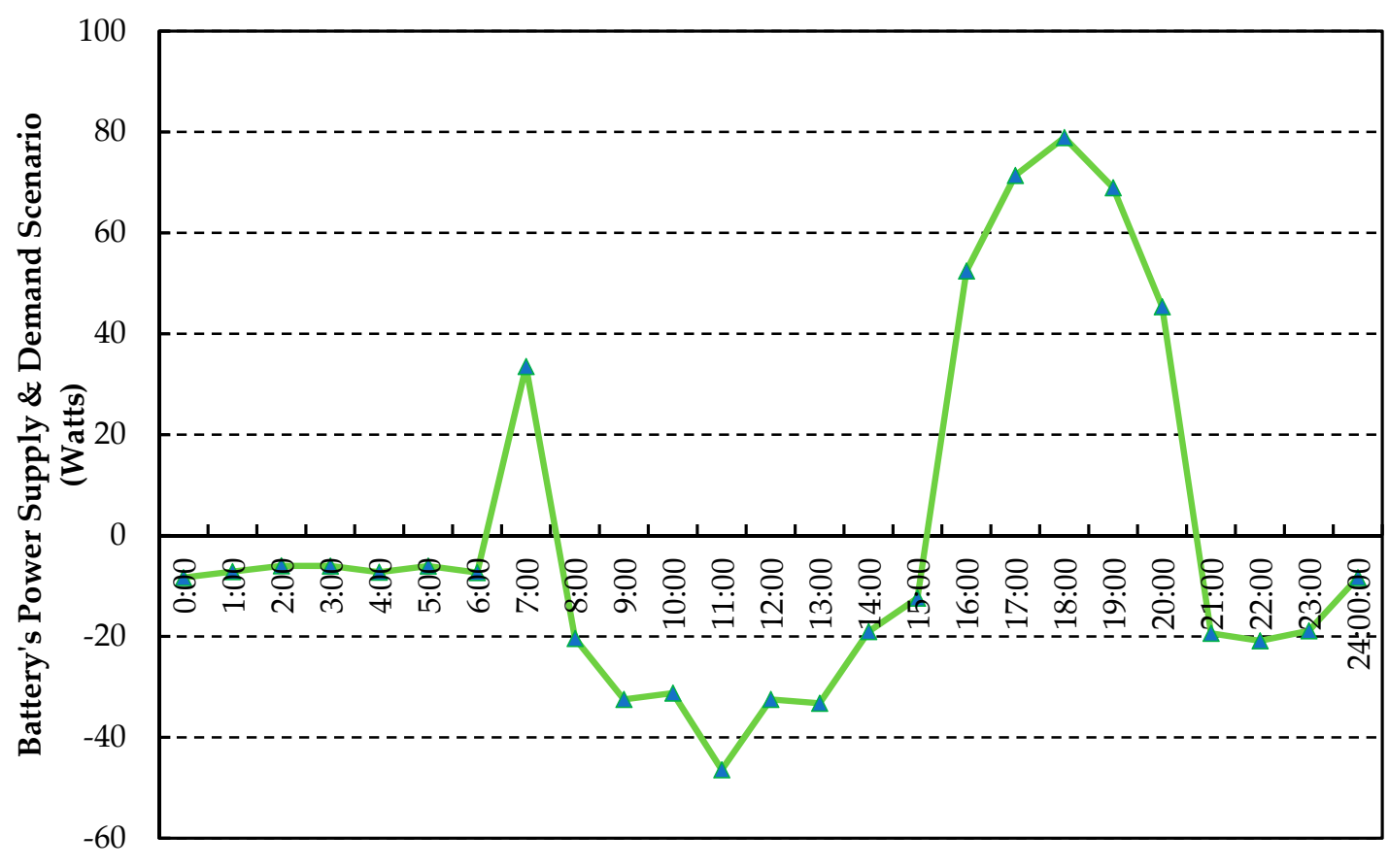

Hours

Figure 6 . The battery operating in both supply and demand modes.

\subsection{Charge Controller Characteristics}

The designed charge controller (CC) offers the main control and protection features for the developed system. As such, during the time when DG units' supplies sufficient energy to the system, the battery gets charged via the charge controller. The charge controller is equipped with the characteristic of overcharge and over-discharge protection of the battery. Hence, when the battery gets fully charged the controller automatically disconnects it from the supply. Similarly, for the times when DG units supply insufficient power to the load, the battery involuntarily start its supply to the load. Concurrently, the charge controller also protects the load against over-voltage and low-voltage 
faults. The charge controller maintains the voltage across load terminals with a variation of $\pm 10 \%$. This amount of variation of voltage in the designed hybrid DCMG system does not produce any adverse effects on the operational performance of the connected load.

\subsection{The Behaviour of the Hybrid DC Microgrid System}

The solar sunshine was available for almost $12 \mathrm{~h}$ for the day of 30 March 2017 as depicted in Figure $4 a$, i.e., from 06:40-18:40 $\mathrm{h}$ of the day. However, due to low solar irradiance, during 06:40-07:30 $\mathrm{h}$ and from 16:00-18:40 h, the PV output is insufficient to meet the load demand as shown in Figure 7. Therefore, during the mentioned time intervals, the battery supports the DG units by supplying its energy and to match the demand. It is also noted that at around 15:00 $\mathrm{h}$ and onwards, high wind speeds enhanced the power output of the WG system suggesting that the WG system actively contributes its power input into the system.

It was found that after continuously working for $5 \mathrm{~h}$ from 16:00 to 21:00 $\mathrm{h}$ of the day, the battery gets fully discharged. In order to protect it from over-discharge, the charge controller automatically disconnects it from the HRES. However, the power contribution of WG is meager compared to that of PV system, as such, after 21:00-h WG system alone cannot carry the load. Though, its power supply is utilised to charge the battery only. It can be seen in the graph in Figure 6, that power supplied by the WG system is almost equal to the battery's power with some amount of losses. In the absence of PV and WG power output, the better performance of battery can be attained if a battery of larger capacity were added to the system.

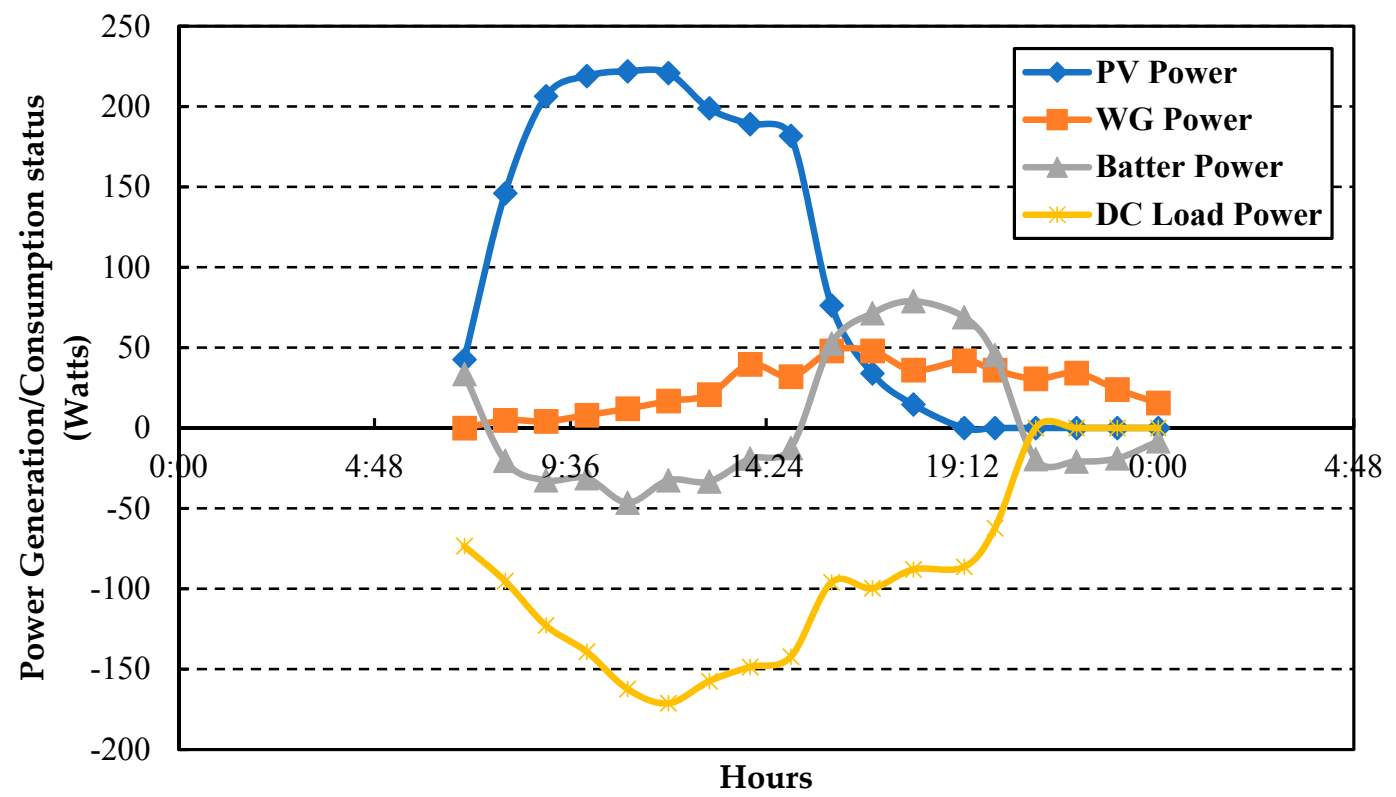

Figure 7. The system components power generation and consumption (Watts) status on dated: 30 March 2017.

The performance of the designed system is experimentally evaluated for consecutive six days from 25 March 2017 to 30 March 2017. Figures 8-12 depict the performance of the developed system for the first five days of the HRES system operation. The graphical representation of the measured data describes the solar irradiation $\left(\mathrm{W} / \mathrm{m}^{2}\right)$ pattern, wind speed $(\mathrm{m} / \mathrm{s})$ and power generation/consumption (Watts) scenario of each of the system component.

The real-time voltages and currents were measured on 25 March 2017 with a multi-clamp meter (Uni-T lamp meter, USA) for solar PV, wind generator, battery and DC loads connected to the system. The power output has been computed with the product of currents and voltages. The measurements 
were taken early morning from 7 a.m. as the sun rises till 8 p.m. of the respective day. The graphical results are depicted in Figure 8c.

In order to get clarity in the measurement and behaviour of the solar and wind generator sets, the global horizontal irradiation in Watt per square meter and wind speed in meters per second was collected from Pakistan solar radiation measurement data [49]. This is depicted in Figure 8a,b. In Figure $8 \mathrm{a}$ the global irradiation from the Sun starts at 6:40 a.m., rises linearly and reaches a maximum of $950 \mathrm{~W} / \mathrm{m}^{2}$ at around 1 p.m. and then decays linearly till 6:30 p.m. Moreover, irregularity has been observed in the wind speed as shown in Figure $8 \mathrm{~b}$ which is in the range of 0.2 to $3 \mathrm{~m} / \mathrm{s}$ from midnight till 11 a.m. The irregular rise in wind speed has been observed from $3 \mathrm{~m} / \mathrm{s}$ to $6.5 \mathrm{~m} / \mathrm{s}$ from 11 a.m. until midnight. The wind speed may vary over different times of the day, week, month or year.

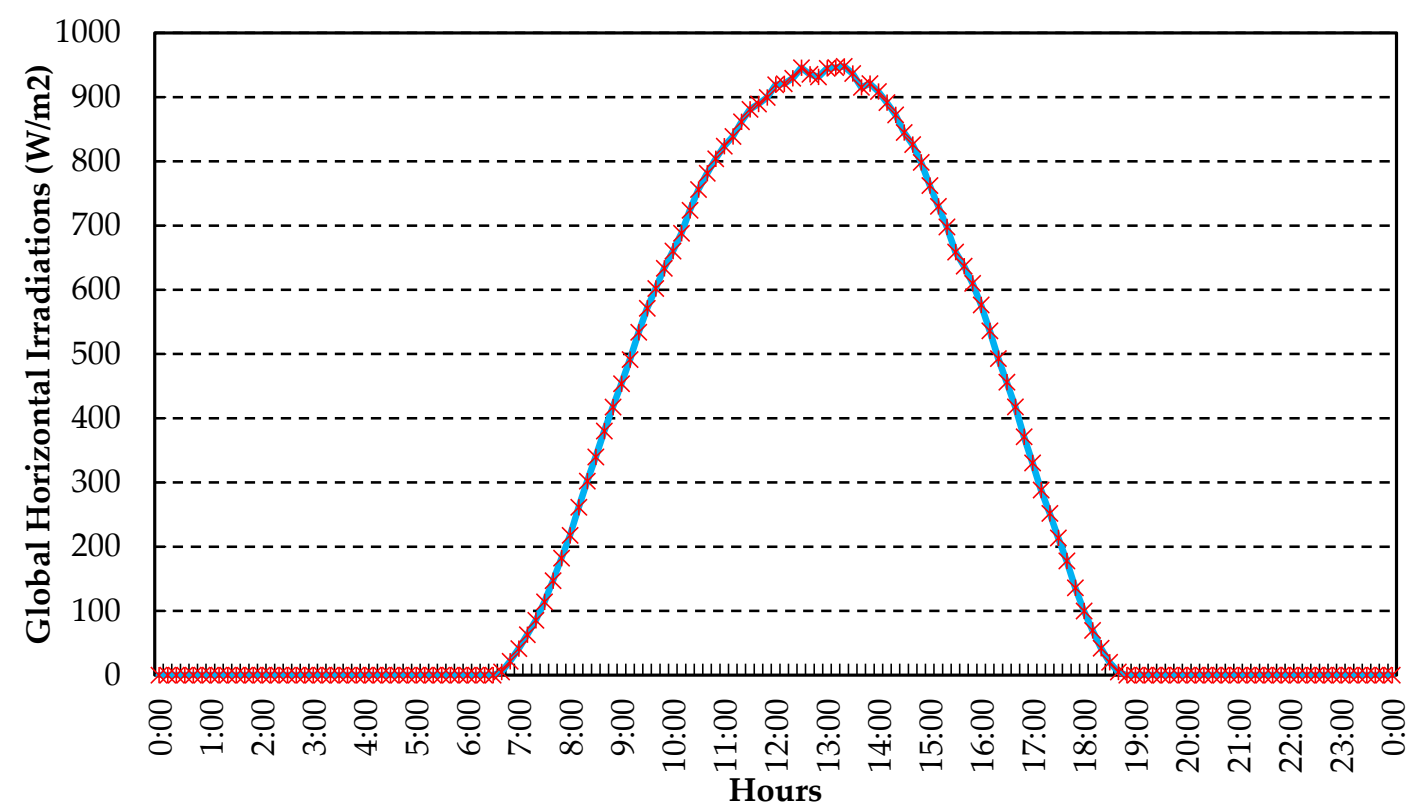

(a)

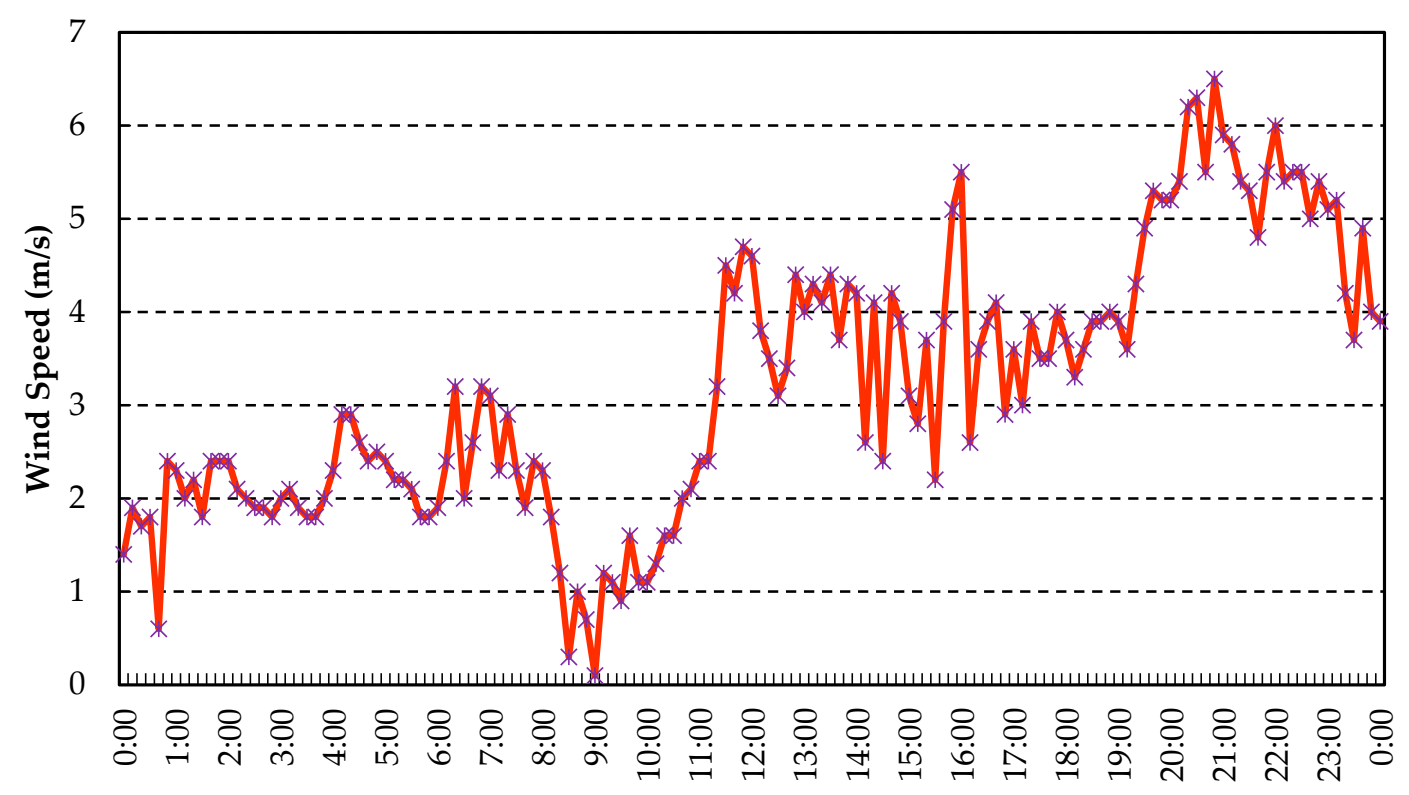

Hours

(b)

Figure 8. Cont. 


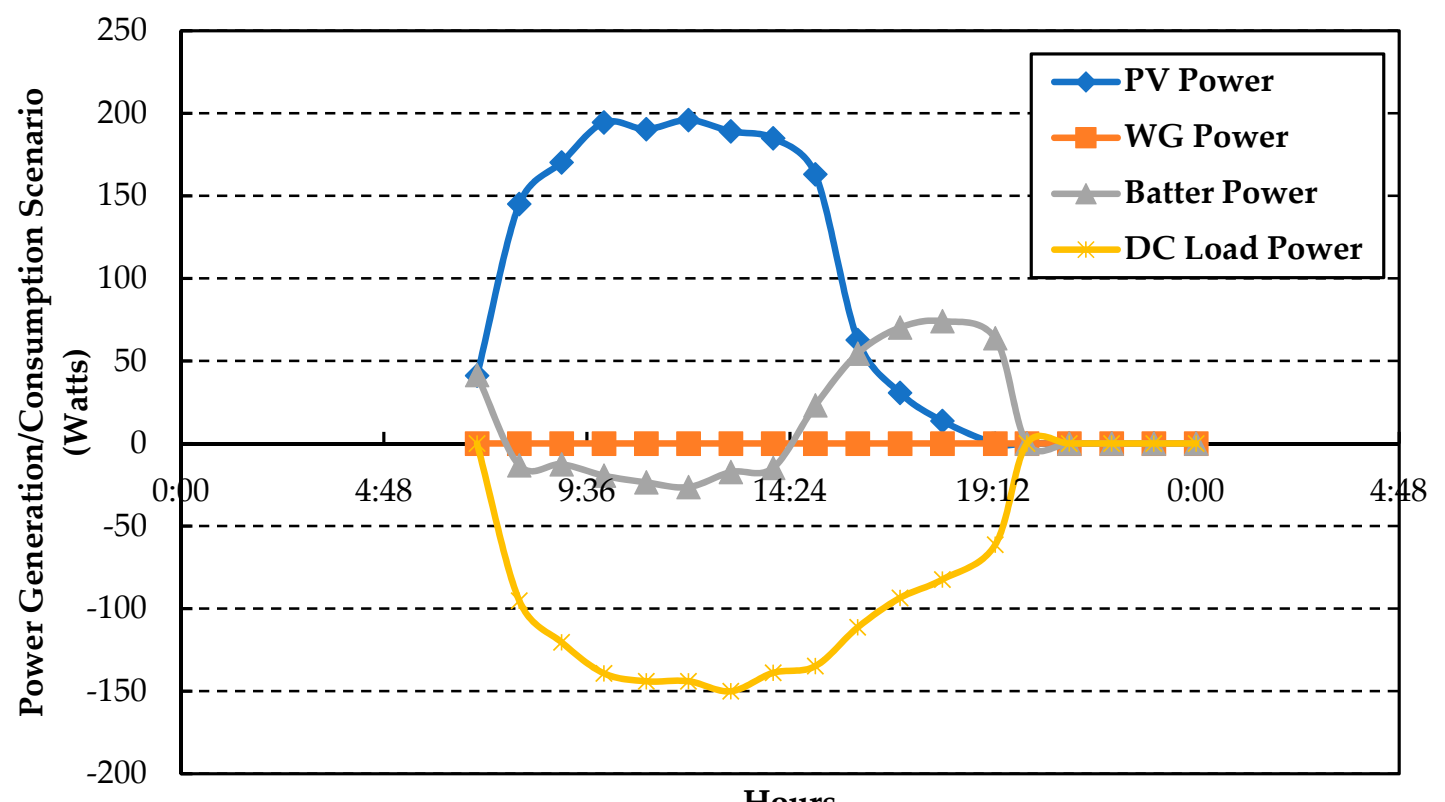

(c)

Figure 8. The solar irradiance, wind speed and power generation/consumption status on 25 March 2017. (a) Solar irradiance $\left(\mathrm{W} / \mathrm{m}^{2}\right)$, (b) Wind speed (m/s), and (c) Power generation/consumption (Watts).

The solar PV output starts from 7 a.m. as the Sun irradiation rises and a power output of 40 Watts as depicted in Figure 8a. The PV output further rises as the solar irradiation rises, and power output reaches approximately up to 200 Watts between 10 a.m. to 3 p.m. The PV output decreases after 3 p.m. and reaches zero watts at around 6:30 p.m. The wind output is zero Watts since morning as the designed system needs a minimum of $2.5 \mathrm{~m} / \mathrm{s}$ wind speed. As evident from Figure $8 \mathrm{~b}$, the wind speed was variable till 11 a.m. and was less than $2.5 \mathrm{~m} / \mathrm{s}$ at some instants. It is logical that there will be no power output from the wind generator in this situation. However, the wind speed was observed to increase continuously from 11 a.m. as shown in Figure 8b, but, the system was unable to provide any output. It was diagnosed that the wind system had some problem relating to lubrication, wind direction and variable speed. The battery backup was getting power from the solar PV and was charging since morning as the system receives the solar irradiance from 7 a.m. till 2:30 p.m. As the PV output reduces, the load is being shared with the PV till 6:30 p.m. After 6:30 p.m. the system was delivered power from the battery backup, which lasts till 7:45 p.m. The system is completely turned off as the voltage reduces below 10.8 volts from the battery, which maintains the battery potential and helps protect the battery from deep discharging. This potential of the battery increases the battery life and system reliability. Moreover, the voltage protection has also been provided at both on the load side and at the battery side to avert the deep discharge for the smooth operation of the system.

The voltages and currents were measured for the day of 26 March 2017, Sunday, for solar PV, wind generator, battery and DC loads connected. The power output has been computed with the product of currents and voltages. The measurements had been taken early morning from 7 a.m. as the sun rises till 7 p.m. of the respective day. The graphical results have been depicted in Figure 9c. The behaviour of solar PV and wind generator can be verified from the global horizontal irradiation in watt per square meter and wind speed in meters per second as collected from the Pakistan solar radiation measurement data [34]. This is depicted in Figure 9a,b. In Figure 9a the global irradiation from the Sun starts at 6:40 a.m. rises linearly and reaches a maximum of $950 \mathrm{~W} / \mathrm{m}^{2}$ at around 1 p.m. and then decays linearly till 6:40 p.m. Moreover, irregularity has been observed in the wind speed as shown in Figure $9 \mathrm{~b}$ which is in the range of 0.2 to $3.5 \mathrm{~m} / \mathrm{s}$ from midnight till 7:20 p.m. An irregular 
rise in wind speed had been observed from $4 \mathrm{~m} / \mathrm{s}$ to $5.5 \mathrm{~m} / \mathrm{s}$ for two hours and the a reduction to a level of less than $4 \mathrm{~m} / \mathrm{s}$ till midnight.

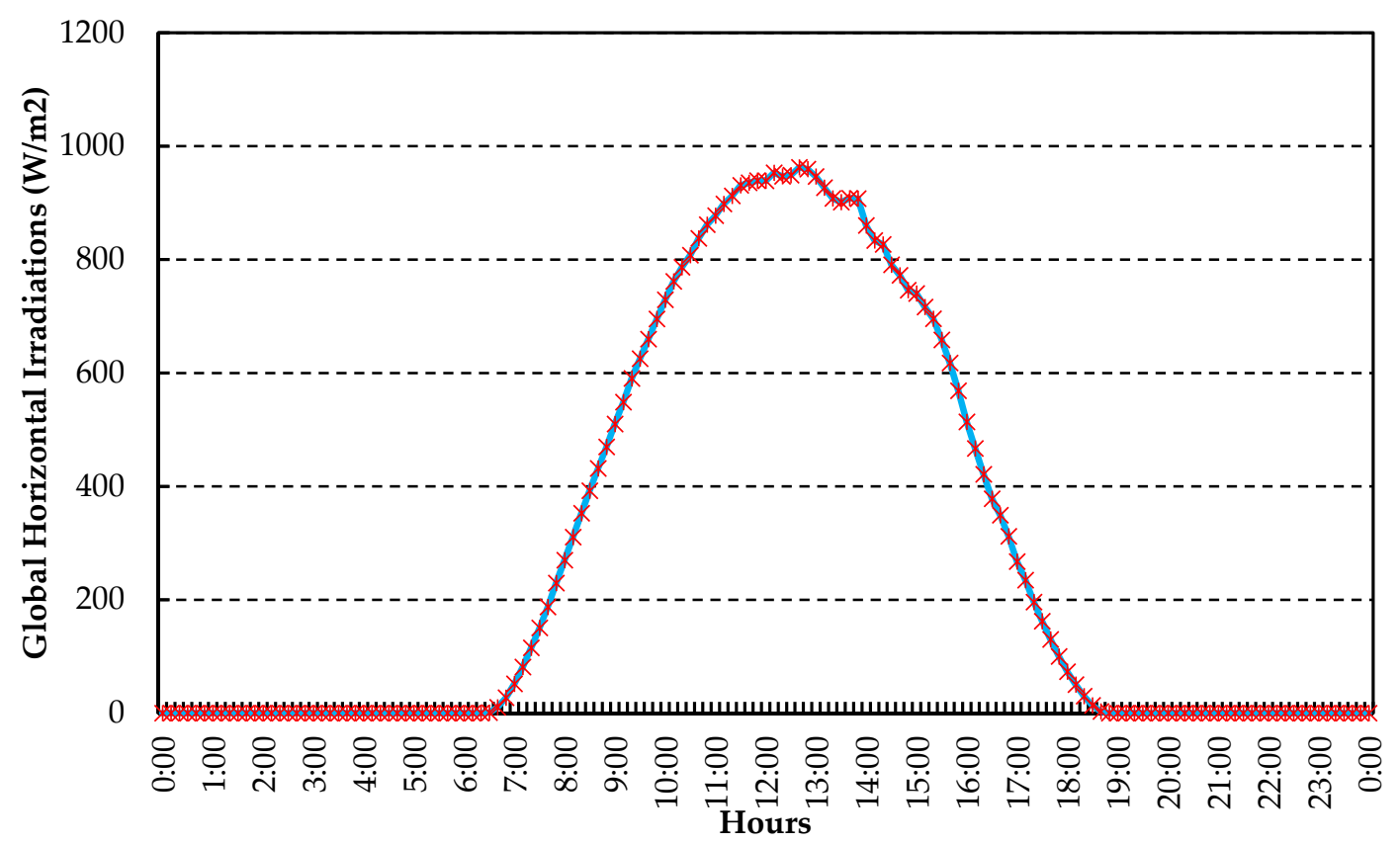

(a)

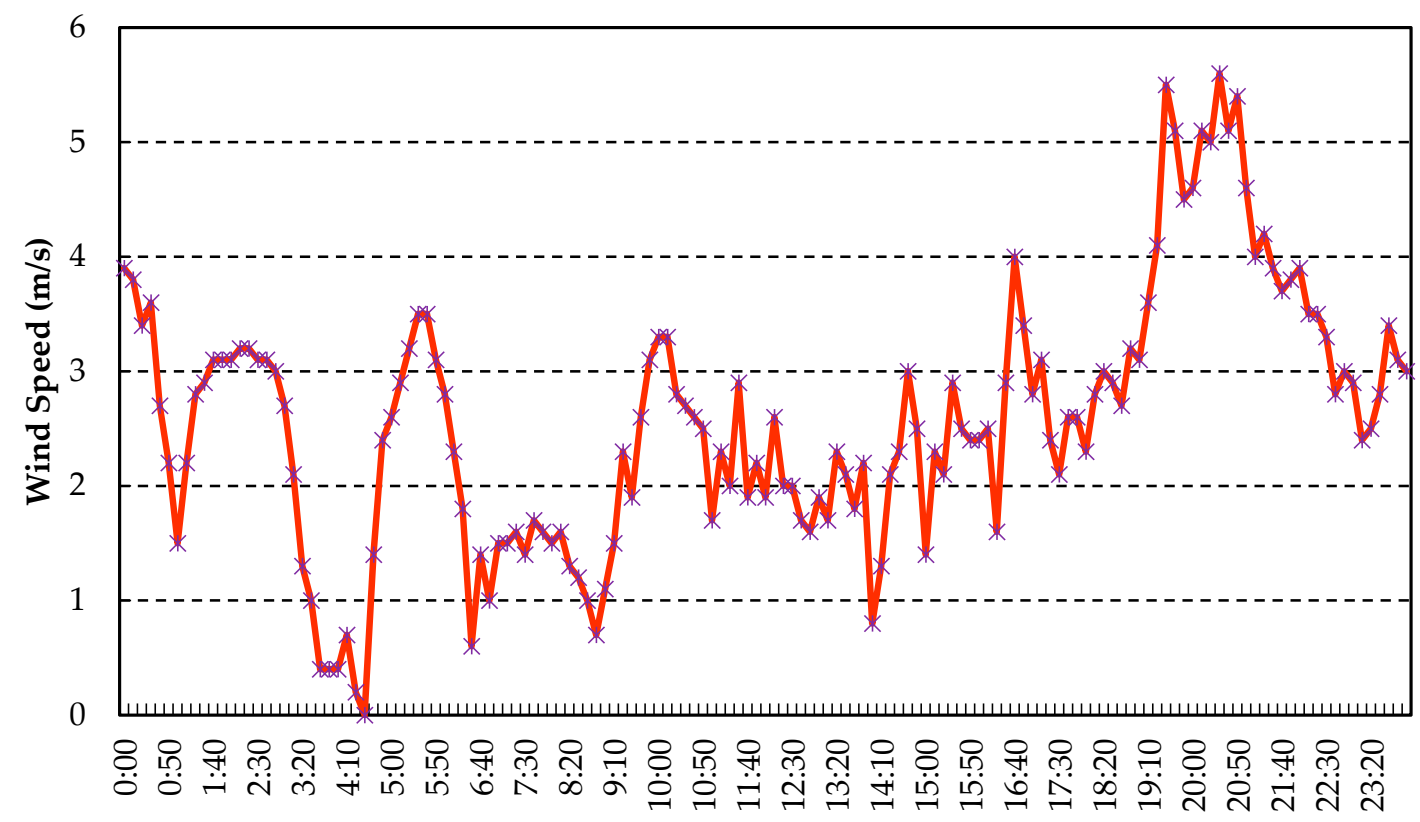

\section{Hours}

(b)

Figure 9. Cont. 


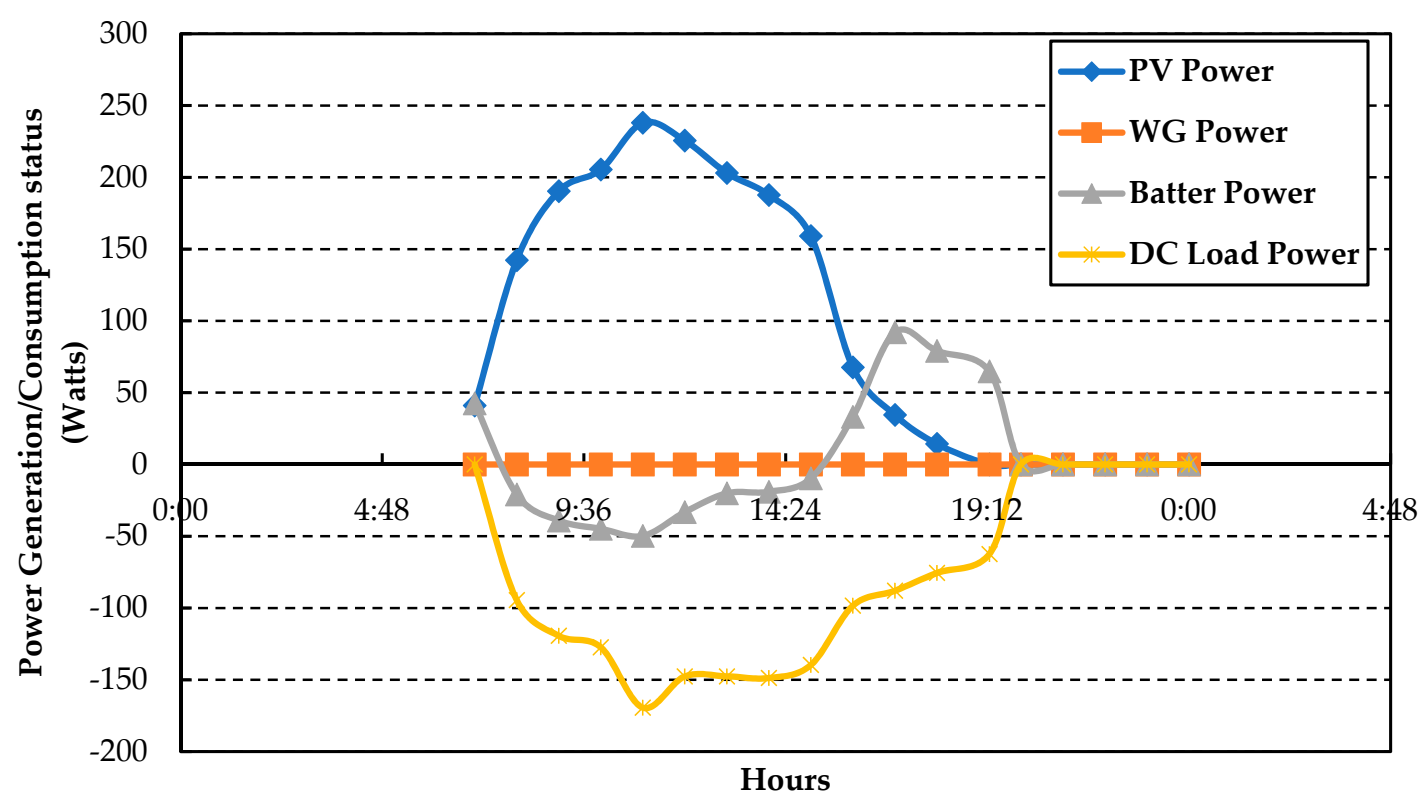

(c)

Figure 9. The solar irradiance, wind speed and power generation/consumption status on 26 March 2017. (a) Solar irradiance $\left(\mathrm{W} / \mathrm{m}^{2}\right)$, (b) Wind speed (m/s) and (c) Power generation/consumption (Watts).

Figure 9a shows the solar PV output of 45 Watts, starting from 7 a.m. The PV output rises further as the solar irradiation rises, and power output reaches $245 \mathrm{~W}$ from around 10:30 a.m. This technically reduces later to $160 \mathrm{~W}$ until 3 p.m. The PV output decreases after 3 p.m. and reaches zero Watts at around 6:30 p.m. The wind output is zero Watts since morning as the designed system needs a minimum of $2.5 \mathrm{~m} / \mathrm{s}$ wind speed. It is also evident from Figure $9 \mathrm{~b}$ that the wind speed was irregular and was only $2.5 \mathrm{~m} / \mathrm{s}$ throughout the day. The battery backup was getting power from the solar PV and was charging since morning as the system starts functioning from 7 a.m. till 3 p.m. After 3 p.m. the PV output reduces drastically, and the load is shared with battery till 6:30 p.m. After 6:30 p.m. the system is completely fed by the battery backup, which lasts till $8: 15$ p.m. The system is completely turned off as the voltage reduces below 10.8 volts from the battery.

Further, in Figure 10, the data collected for the day of 27 March 2017, Monday is given which pertain to the voltages and currents of the day as well as relating to the solar PV, wind generator, battery and DC loads connected to the system. These measurements were taken early morning from 7 a.m. as the Sun rises till 2 a.m. of the next day. The graphical results are accordingly depicted in Figure 10c.

The global horizontal irradiation in watt per square meter and wind speed in meters per second has been collected from Pakistan solar radiation measurement data [32]. This is depicted in Figure 10a,b. The global Sun irradiation started at 6:35 a.m., rises linearly and reaches a maximum value of $1000 \mathrm{~W} / \mathrm{m}^{2}$ at around 11:20 a.m. and remains at peak till 1:30 p.m. and then decays linearly till 6:40 p.m. The variable wind speed has been observed as shown in Figure 10b, which is of $3 \mathrm{~m} / \mathrm{s}$ for $6 \mathrm{~h}$ from midnight and huge variations are shown from 7 a.m. till midnight with peaks up to $6.5 \mathrm{~m} / \mathrm{s}$.

The solar PV output starts from 7 a.m. as Sun irradiation rises at around 45 Watts on 27 March 2017 as depicted in Figure 10a. The PV output rises as the solar irradiation rises, and power output reaches till 240 Watts from around 10 a.m. and lasts till 1:30 p.m. The PV output decreases slowly after 3 p.m. and reaches zero Watts at around 6:30 p.m. The wind output is zero Watts since morning as the designed system needs a minimum of $2.5 \mathrm{~m} / \mathrm{s}$ wind speed. In Figure 10b, the wind speed was variable, and subsequently, variations in the power output of the wind power generation were observed.

The battery backup was getting power from the solar PV and was under charging since morning as the system starts functioning from 7 a.m. till 2:30 p.m. As the PV output reduces, the load is being 
shared by the battery backup with PV till 6:30 p.m. After 6:30 p.m. the system is wholly dealt with battery backup, which lasts till 7:45 p.m. The system is completely turned off as the voltage reduces below 10.8 volts from the battery, which maintains the battery potential and helps protect the battery from deep discharging.

The voltages and currents for the day of Tuesday 28 March 2017, have been measured with a multi-clamp meter (Uni-T Clamp meter) for solar PV, wind generator, battery and connected DC loads. The power output has been computed with the product of currents and voltages. The measurements were taken early morning from 7 a.m. as the Sun rises till 8 p.m. of the respective day. The graphical results have been depicted in Figure 11c.

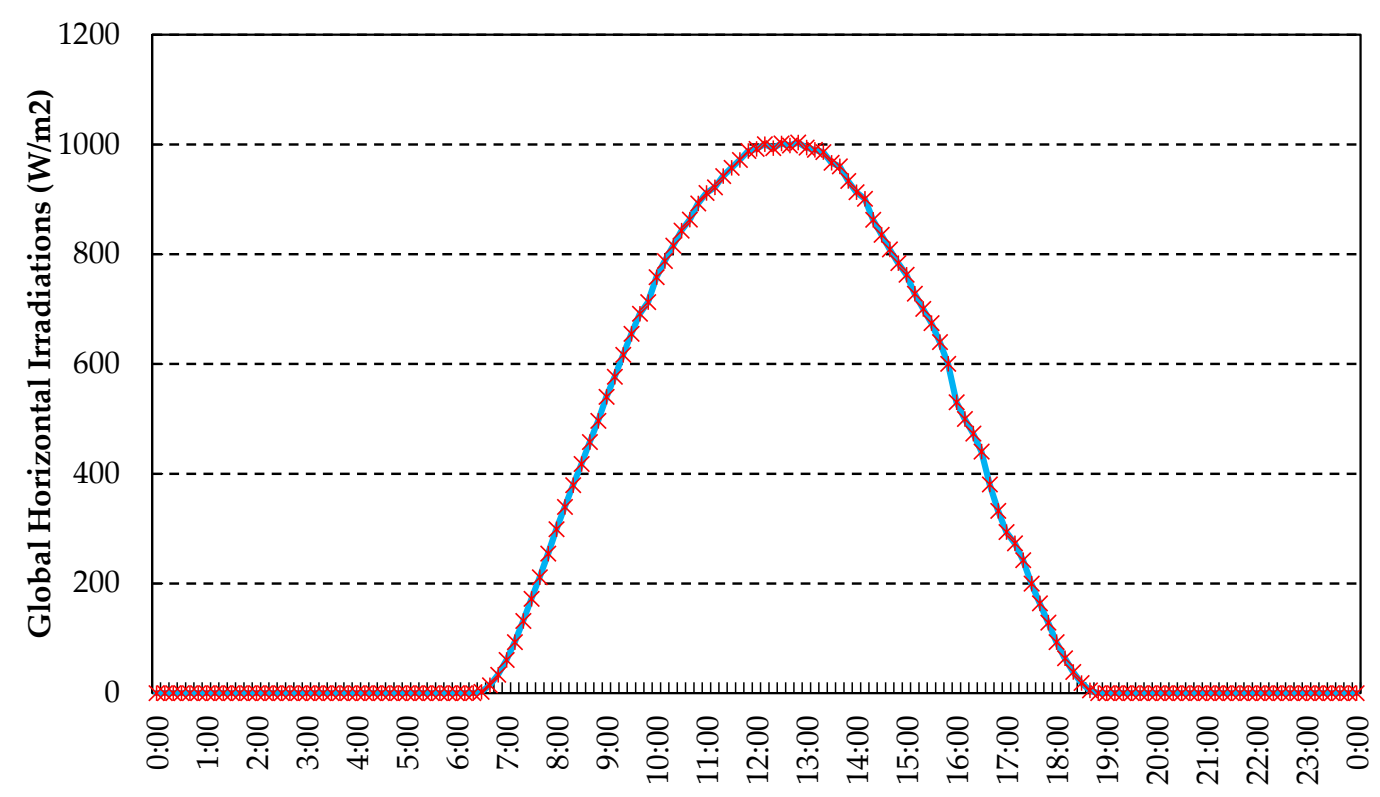

Hours

(a)

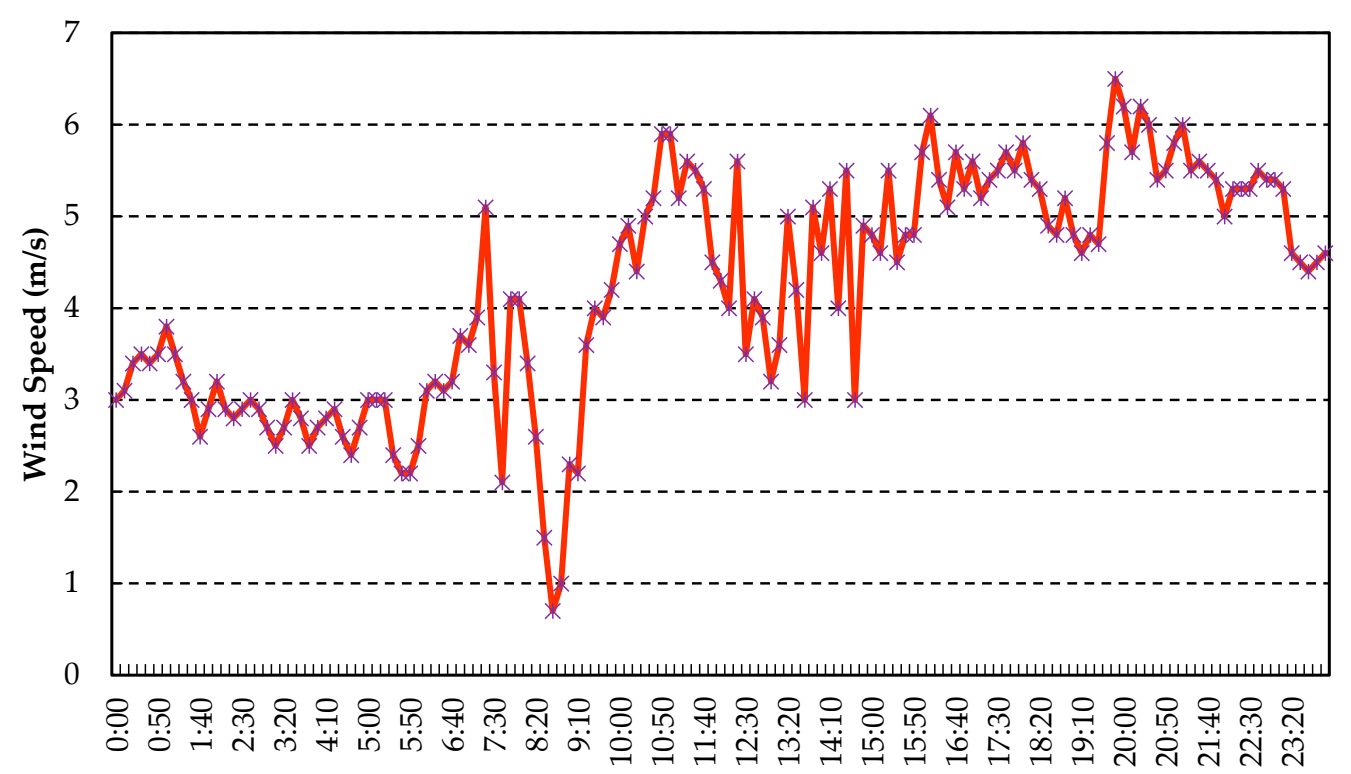

Hours

(b)

Figure 10. Cont. 


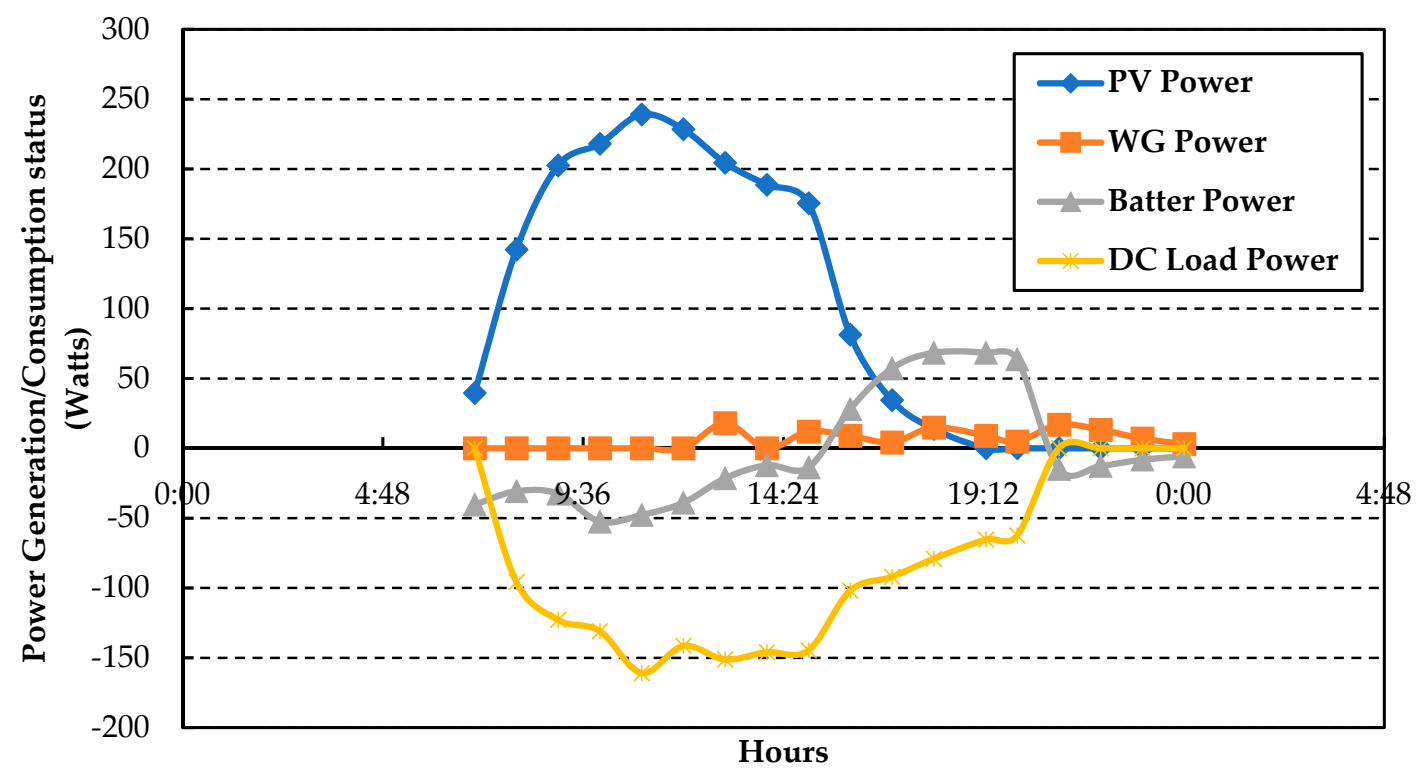

(c)

Figure 10. The solar irradiance, wind speed and power generation/consumption status on 27 March 2017. (a) Solar irradiance $\left(\mathrm{W} / \mathrm{m}^{2}\right)$, (b) wind speed $(\mathrm{m} / \mathrm{s})$ and (c) power generation/consumption status (Watts).

The global horizontal irradiation in watt per square meter and wind speed in meters per second has been collected from Pakistan solar radiation measurement data [34]. This is depicted in Figure 11a,b. In Figure 11a, the global irradiation from the Sun starts at 6:40 a.m., rises linearly and reaches a maximum of $1000 \mathrm{~W} / \mathrm{m}^{2}$. Moreover; irregularity has been observed in the wind speed which attains a peak of $10 \mathrm{~m} / \mathrm{s}$ for short period of time in the evening, as shown in Figure 11b.

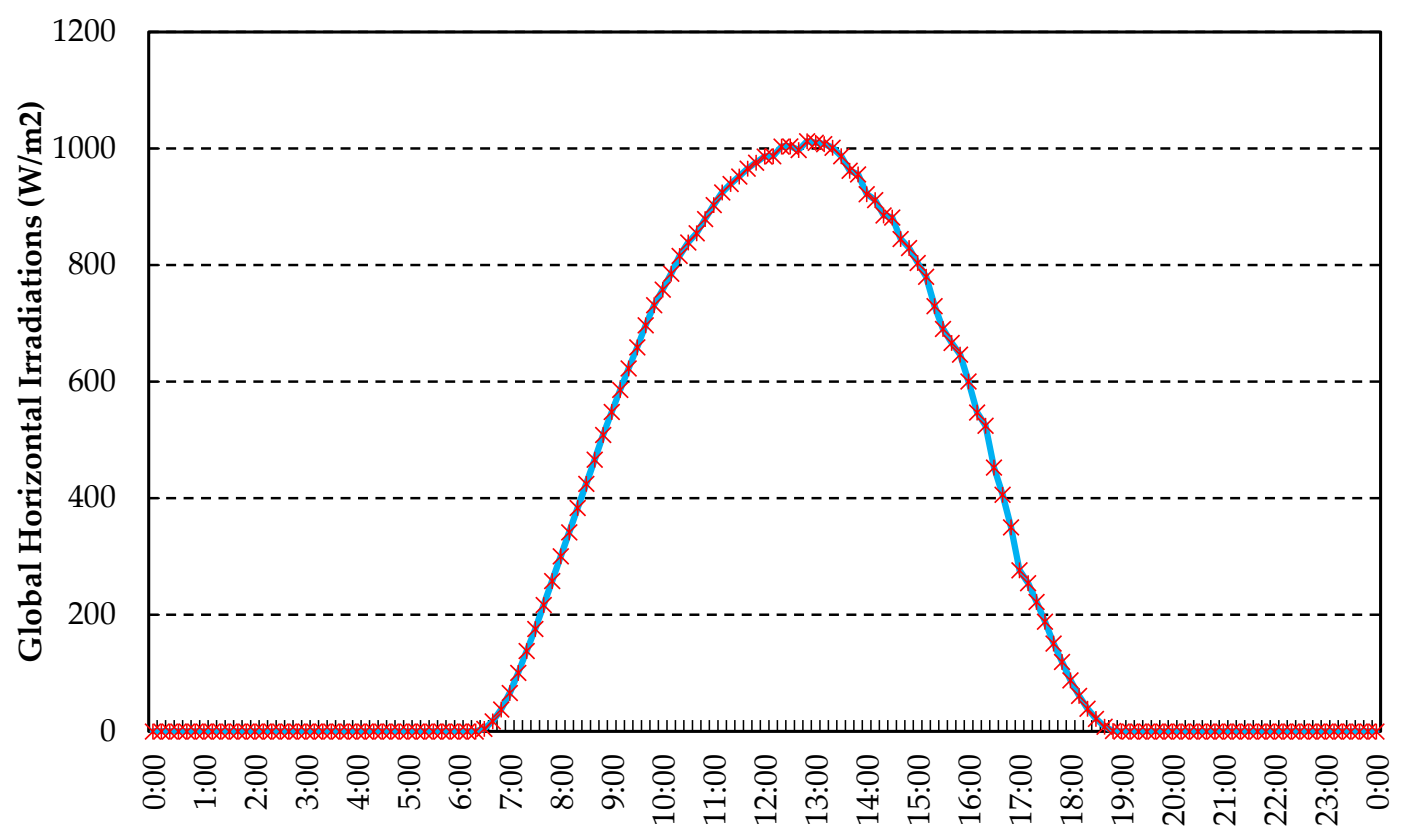

Hours

(a)

Figure 11. Cont. 


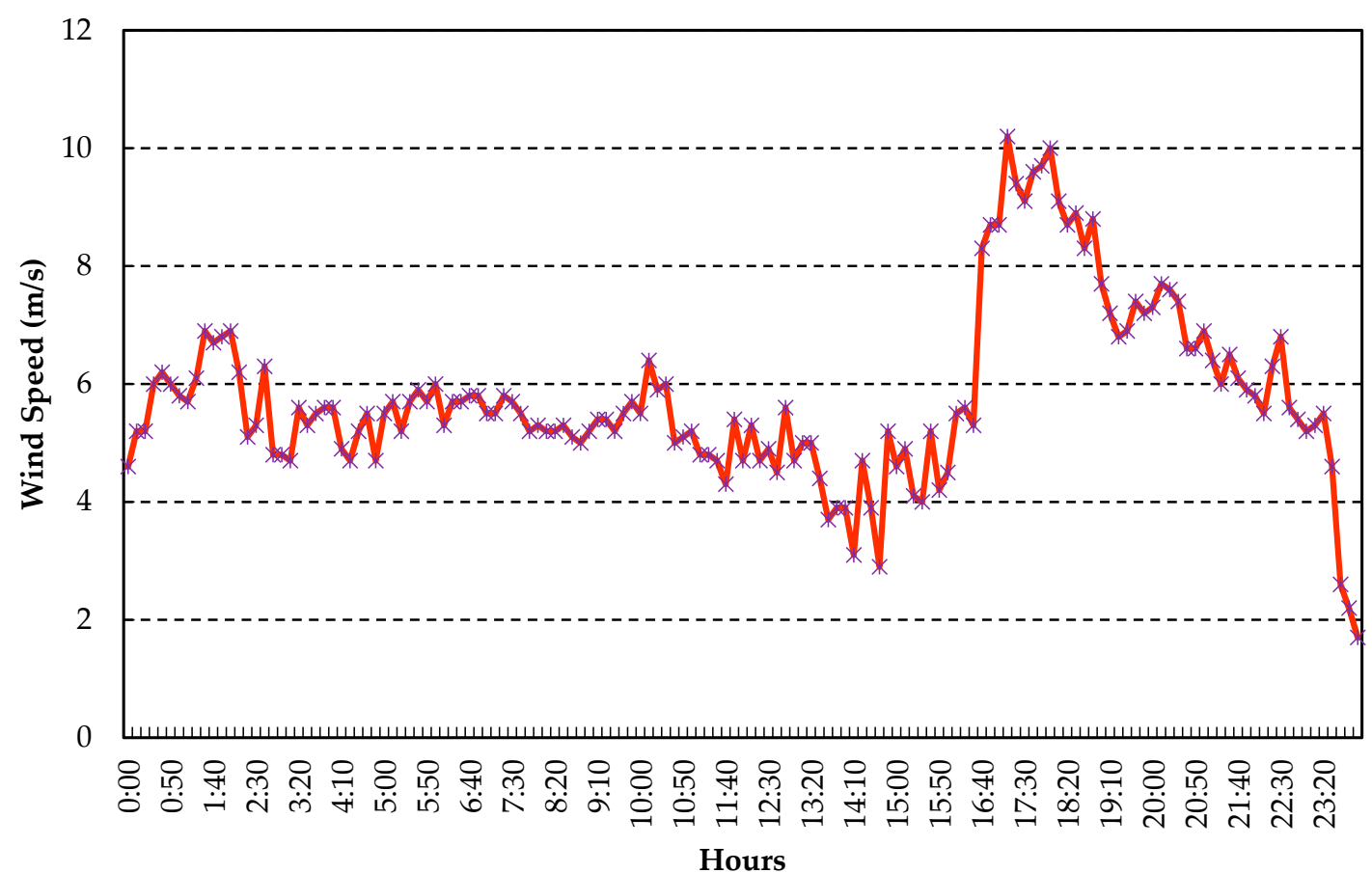

(b)

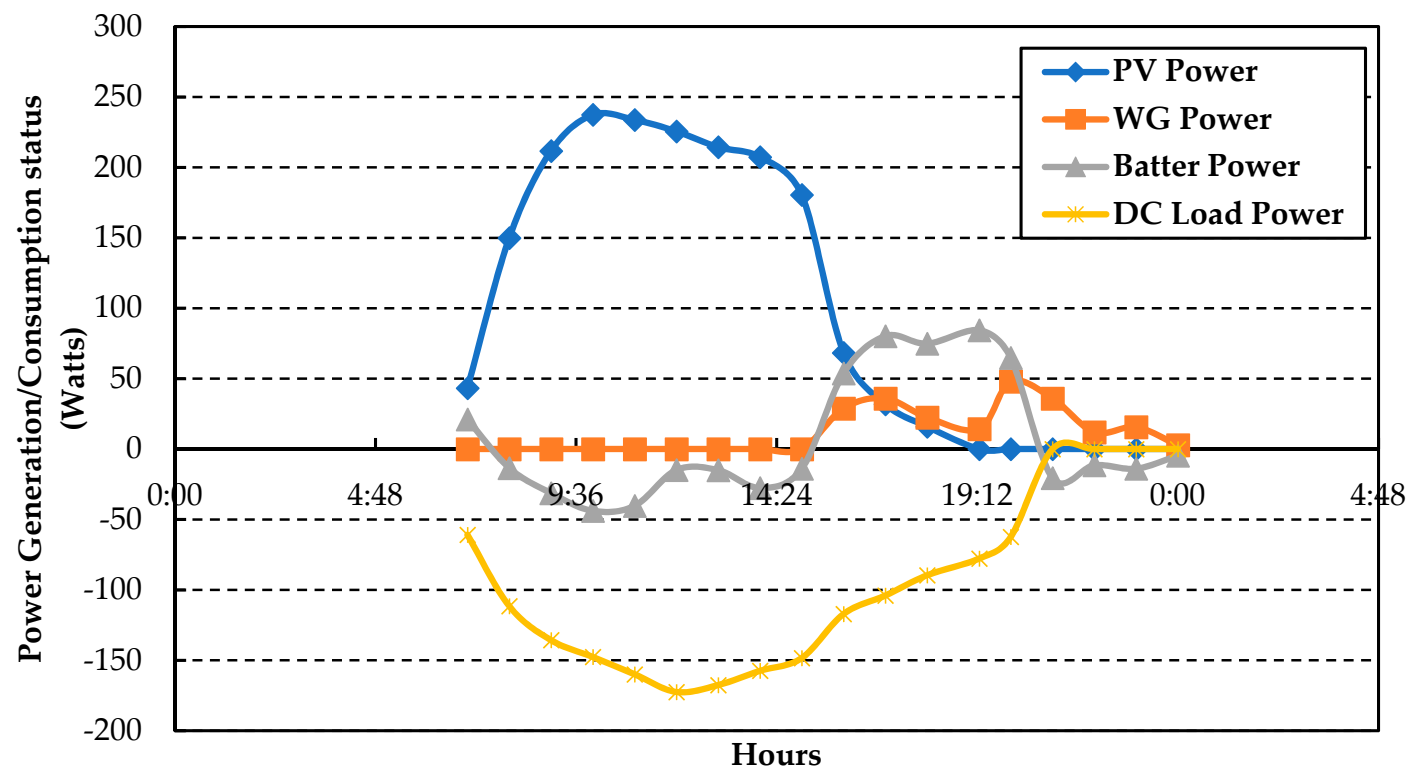

(c)

Figure 11. The solar irradiance, wind speed and power generation/consumption status on 28 March 2017. (a) Solar irradiance $\left(\mathrm{W} / \mathrm{m}^{2}\right)$, (b) Wind speed $(\mathrm{m} / \mathrm{s})$ and (c) Power generation/consumption (Watts).

The solar PV output is 46 Watts at 7 a.m. as Sun irradiation rises as depicted in Figure 11a. The PV output further rises as the solar irradiation rises, and power output reaches 245 Watts from around 9:45 a.m. and lasts for a short time. The PV output decreases after 3 p.m. and reaches zero watts at around 6:45 p.m. The wind output is zero Watts since morning as the designed system needs a minimum of $2.5 \mathrm{~m} / \mathrm{s}$ wind speed. Since, from Figure $11 \mathrm{~b}$ wind speed was less at that time, and wind output can be seen after 3:30 p.m. since wind speed had increased. The battery backup was getting power from the solar PV and is charging since morning as the system gets started from 7 a.m. till 2:30 p.m. As the PV output reduces the load is shared with the PV system till 6:30 p.m. After 6:30 p.m. 
the system is completely supplied with battery backup, which lasts till 7:45 p.m. The system is completely turned off as the voltage reduces below 10.8 volts from the battery.

The voltages and currents for the day of Sunday 29 March 2017, were also measured with a multi-clamp meter (Uni-T Clamp meter) for solar PV, wind generator, battery and DC loads connected. The power output was computed with the product of currents and voltages. The measurements were taken early morning from $7 \mathrm{a} . \mathrm{m}$. as the Sun rises till $8 \mathrm{p} . \mathrm{m}$. of the respective day. The graphical results have been depicted in Figure 12c. The global horizontal irradiation in watt per square meter and wind speed in meters per second has been collected from Pakistan solar radiation measurement data [34]. This is depicted in Figure 12a,b. In Figure 12a, the global irradiation from the Sun starts at 6:40 a.m., rises linearly and reaches at a maximum of $950 \mathrm{~W} / \mathrm{m}^{2}$ at around 1 p.m. and decays linearly till 6:30 p.m. Moreover, irregularity has been observed in the wind speed which is in the range of 0.2 to $3 \mathrm{~m} / \mathrm{s}$ from midnight till 11 a.m., as shown in Figure 12b. An irregular rise in wind speed has been observed from $3 \mathrm{~m} / \mathrm{s}$ to $6.5 \mathrm{~m} / \mathrm{s}$ from 11 a.m. until midnight.

The solar PV output of $40 \mathrm{MW}$ is produced from 7 a.m. as the Sun irradiation rises. This is depicted in Figure 12a. The PV output rises as the solar irradiation rises, and power output reaches till 200 Watts from around 10 a.m. and lasts till 3 p.m. The PV output decreases after 3 p.m. and reaches zero Watts at around 6:30 p.m. The wind output is zero Watts since morning as the designed system needs a minimum of $2.5 \mathrm{~m} / \mathrm{s}$ wind speed. It is evident from Figure $12 \mathrm{~b}$ that wind speed was variable till 11 a.m. and less than $2.5 \mathrm{~m} / \mathrm{s}$ at some instants. It ss logical that there will be no power output from the wind generator at this wind speed. However, as the wind speed increases irregularly from 11 a.m. as shown in Figure 12b, yet the wind power generation system was unable to generate any power. It was analyzed later that the wind system has some problems with lubrication, wind direction and variable speed.

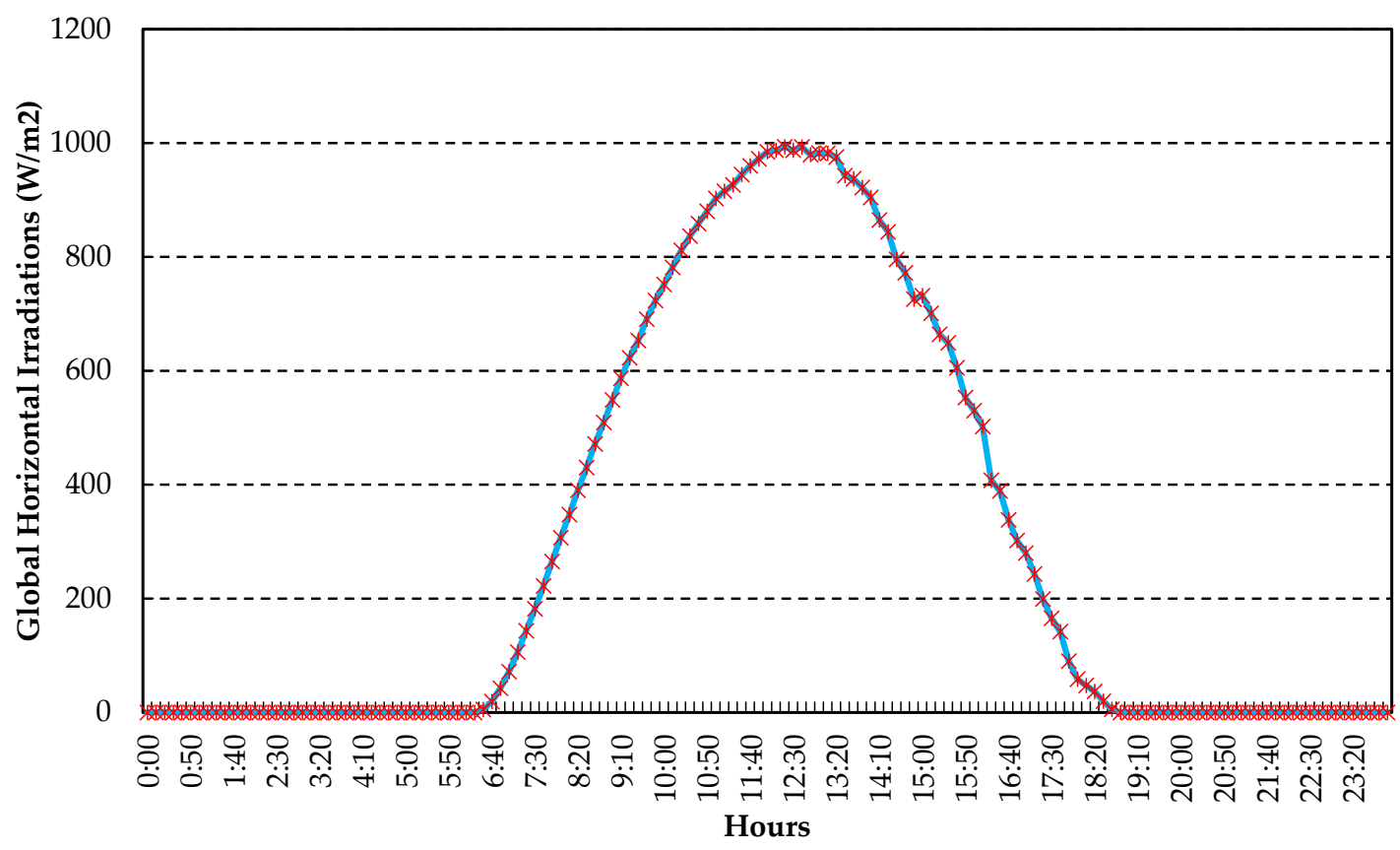

(a)

Figure 12. Cont. 


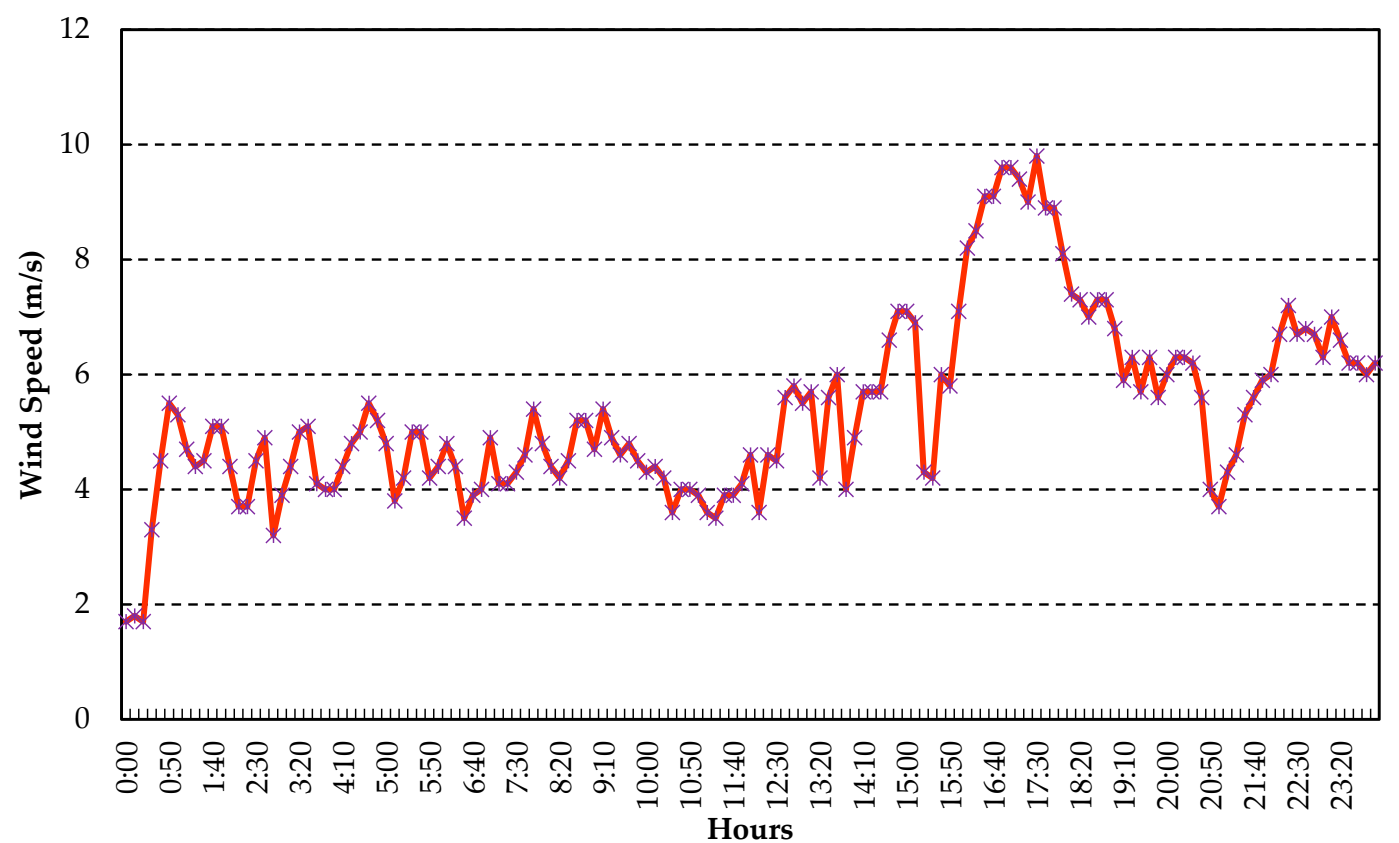

(b)

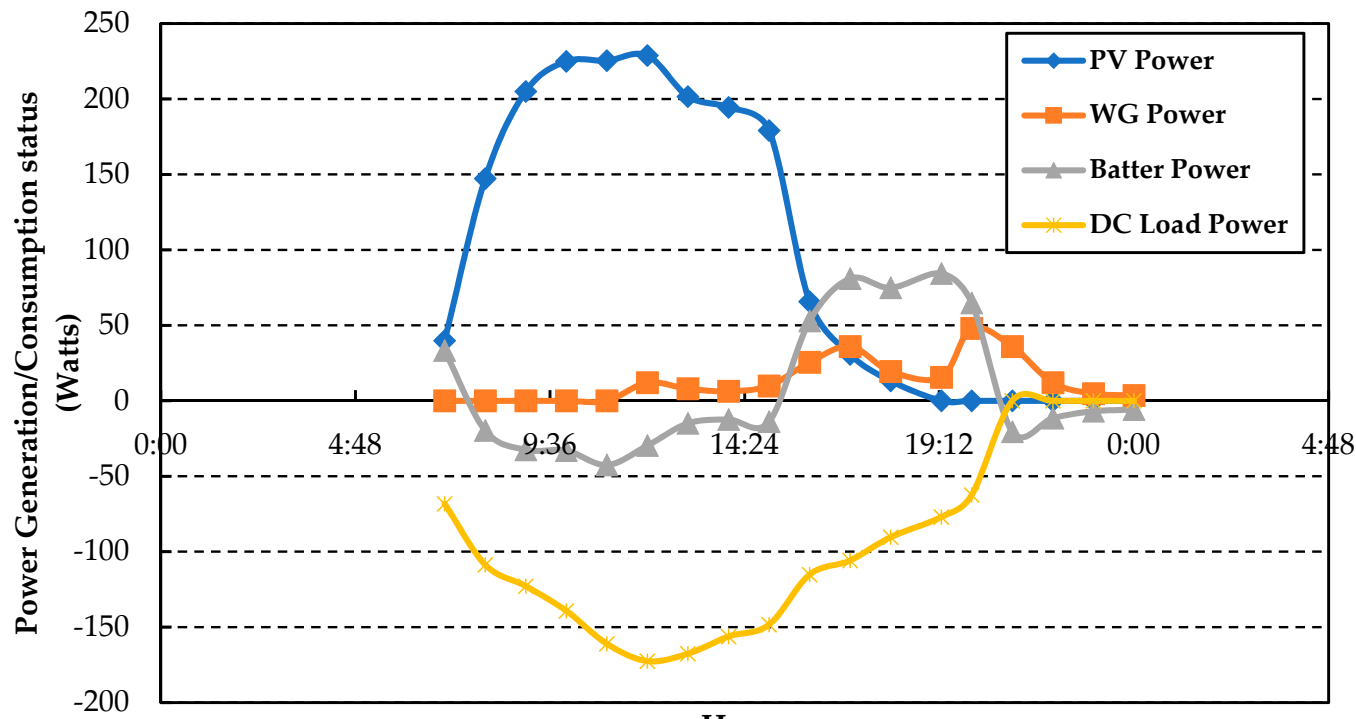

(c)

Figure 12. The solar irradiance, wind speed and power generation/consumption status on 29 March 2017. (a) Solar irradiance $\left(\mathrm{W} / \mathrm{m}^{2}\right)$, (b) wind speed (m/s), (c) power generation/consumption (Watts).

The battery backup was getting power from the solar PV and is charging since morning as the system gets started from 7 a.m. till 2:30 p.m. As the PV output reduces, the load was shared with PV till 6:30 p.m. After 6:30 p.m. the system is wholly supplied with battery backup, which lasts till 7:45 p.m. The system is completely turned off as the voltage reduces below 10.8 volts from the battery, which maintains the battery potential and helps protect the battery from deep discharging.

Therefore, it has been observed that the DC microgrid system operates satisfactorily from morning till evening up till the battery is supporting the load. The optimal consumption of battery would increase the backup time for the load to be dealt. In order to further strengthen the idea of a hybrid DC microgrid a financial analysis has been carried out. The levelised cost of energy along with discounted payback have been computed for the proposed system and diesel generator system. 


\section{Levelised Cost of Energy (LCOE) Analysis of the Designed Hybrid DCMG System}

The LCOE, ratio of total expended cost on energy generation to the total generated electrical energy, is a valuable tool to compare the technologies with unique operating characteristics. For any project, it is the lowest cost of energy at which the energy must be sold to cover the expenses, i.e., to have a zero present value [50]. The general mathematical relationship to calculate LCOE is given as Equation (1) [51]. As per the above-stated definition, the LCOE can be calculated as Equation (2). The LCOE analysis of the designed renewable energy based hybrid DCMG system accounts for the capital cost, operating cost and the kWh electricity generated by this system over its lifetime. The capital cost of the system includes the equipment's purchase and their installation costs whereas the operating cost is based on the operation and maintenance costs of the system. The lifetime of the hybrid DCMG system is assumed to be of 20 years. After determining the LCOE cost of the designed hybrid DCMG system, a comparative LCOE analysis of same with the conventional gasoline generator set of same capacity and lifetime have been undertaken in this study.

$$
\mathrm{LCOE}=\frac{\sum_{t=0}^{n} \frac{I_{t}+M_{t}}{\left(I_{0}+r\right)^{t}}}{\sum_{t=0}^{n} \frac{E_{t}}{\left(I_{0}+r\right)^{t}}}
$$

where $I_{t}=$ Investments at time $t ; M_{t}=$ Operation and Maintenance costs at time $t ; E_{t}=$ Energy generation at time $t ; r=$ Evaluation discount rate and $t=$ time, from 0 to $n$

Operation and Maintenance Costs of Hybrid DCMG System

The LCOE analysis of the designed system installation and operation costs of each of its component are undertaken based on the following hypothesis;

- As the PV and BESS are static components hence they require no essential maintenance during their lifetime. Therefore, the maintenance cost of this equipment is assumed as zero in this study.

- Since the WG system has moving parts which result in more wear and tear thus it requires a substantial maintenance cost. However, the maintenance cost of the WG system regarding any significant repair work in its lifetime is ignored. Instead, the routine service and maintenance of the WG system per year at the rate of $5 \%$ of the equipment's capital cost are taken into consideration.

- In addition, it is considered that BESS will be replaced after every 3 years as the performance of the battery decays with time. An increment of $5 \%$ of the replaced battery's cost is counted into the cost of the new battery.

- Finally, a 5\% of the CC's cost is also inlcuded into a maintenance cost per year for the situations if any electronic component needs to be replaced in its circuitry.

The capital and running costs of the hybrid DCMG system are given in Table 4. The graphical illustration in Figure 13 sws the percentage share of each component in the total cost of the system for the 20 years. Moreover, Figure 14 shows the percentage share of capital and running costs in the total cost of the hybrid DCMG system. It is evident from these graphical illustrations that the battery represents a major part in the cost of hybrid DCMG system, with a share of more than $30 \%$. 
Table 4. The capital and running costs of the proposed hybrid DCMG system.

\begin{tabular}{|c|c|c|c|c|}
\hline Sr. \# & Equipment & $\begin{array}{c}\text { Capital } \\
\text { (Equipment) } \\
\text { Cost (PKR) }\end{array}$ & $\begin{array}{c}\text { Running } \\
\text { (Maintenance/Replacement) } \\
\text { Cost (PKR) }\end{array}$ & Total Cost (PKR and \$) \\
\hline 1. & $\begin{array}{c}\text { Photovoltaic } \\
\text { Plates (PV) }\end{array}$ & $6500 \times 3=19,500 /-$ & - & $\begin{array}{c}19,500 /-P K R \\
(\$ 185)\end{array}$ \\
\hline 2. & $\begin{array}{l}\text { Wind Generator } \\
\qquad(\mathrm{WG})\end{array}$ & $20,000 /-$ & $\begin{array}{l}500 \times 20=10,000 /-\mathrm{PKR} \text { (at } 5 \% \\
\quad \text { of initial cost per year) }\end{array}$ & $\begin{array}{c}20,000+10,000= \\
30,000 /-P K R \\
(\$ 285)\end{array}$ \\
\hline 3. & $\begin{array}{l}\text { Battery Energy } \\
\text { Storage System } \\
\quad \text { (BESS) }\end{array}$ & $4500 /-$ & $\begin{array}{c}\text { 32,000/-PKR (battery replaced } \\
\text { after every } 3 \text { years' time with } \\
5 \% \text { increase in its cost) }\end{array}$ & $\begin{array}{c}4500+32,000= \\
36,500 /-\mathrm{PKR} \\
(\$ 347)\end{array}$ \\
\hline 4. & $\begin{array}{c}\text { Charge } \\
\text { Controllers (CCs) }\end{array}$ & $8000 /-$ & $\begin{array}{c}400 \times 20=8000 /- \text { PKR }(\text { at } 5 \% \\
\text { of initial cost per year) }\end{array}$ & $\begin{array}{l}8000+8000= \\
16,000 /-P K R \\
(\$ 152)\end{array}$ \\
\hline 5. & $\begin{array}{l}\text { Photovoltaic and } \\
\text { Wind Generator } \\
\text { Stands }\end{array}$ & $12,000 /-$ & - & $\begin{array}{l}12,000 /-P K R \\
(\$ 114)\end{array}$ \\
\hline 6. & Cable & $2000 /-$ & - & $\begin{array}{c}\text { 2000/-PKR } \\
(\$ 19)\end{array}$ \\
\hline & Total & $\begin{array}{c}66,000 /- \\
(\$ 627)\end{array}$ & $\begin{array}{c}50,000 /-P K R \\
(\$ 475)\end{array}$ & $\begin{array}{c}116,000 /-P K R \\
(\$ 1102)\end{array}$ \\
\hline
\end{tabular}

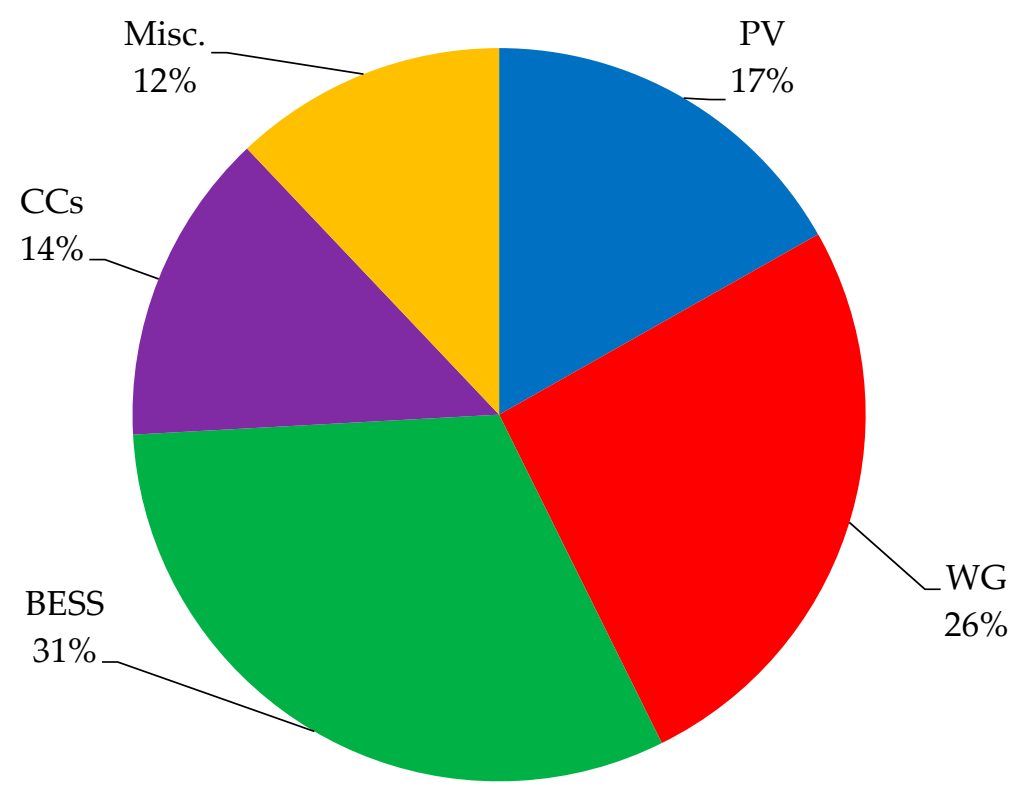

Figure 13. The \%age share of each component in the total cost of hybrid DCMG system for 20 years lifetime.

Table 5 presents the cumulative cost, cumulative kilowatt hours $(\mathrm{kWh})$ generated of the hybrid DCMG system over a period of 20 years. This data would be required to compute the Levelised Cost of Energy (LCOE) for comparing the expected generation from the proposed hybrid DC microgrid system. Based on these calculations for the lifetime of 20 years, LCOE of the designed renewable energy based hybrid DCMG system is estimated by using the Equation (2):

$$
\text { LCOE of hybrid DCMG system }=\frac{\text { Cumulative cos } t \text { of the system }}{\text { Cumulative } k W h ' s \text { generated by the system }}
$$




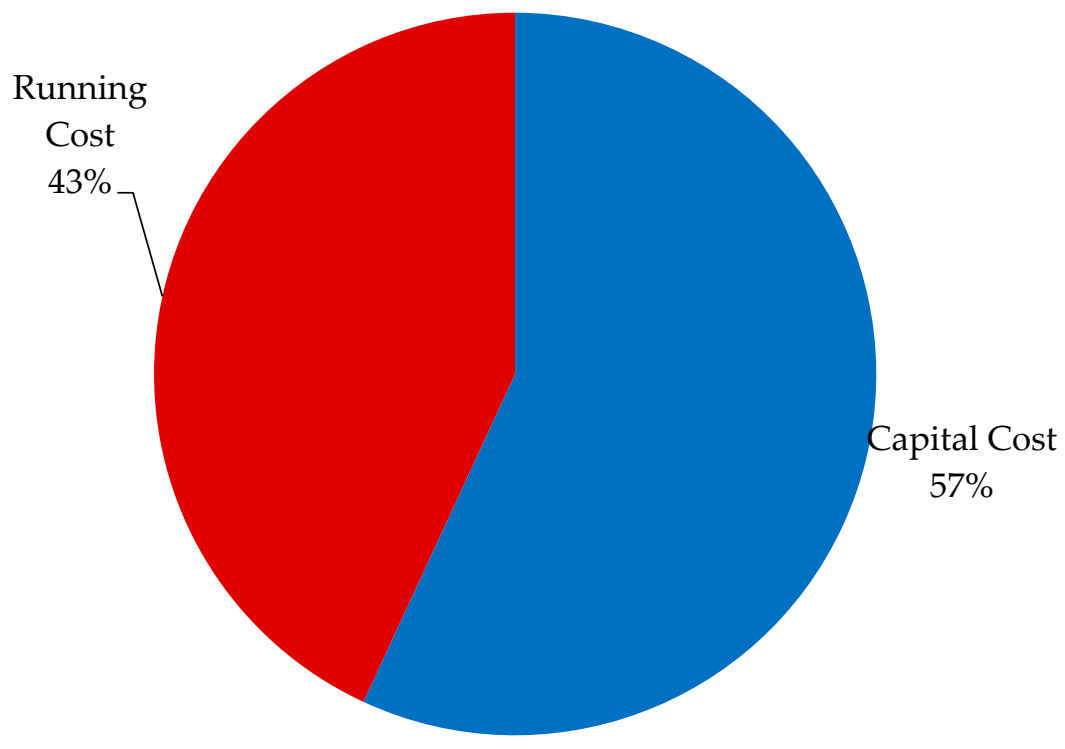

Figure 14. The \%age share of capital and running costs in the total cost of hybrid DCMG system for 20 years' lifetime.

Table 5. The estimated cumulative cost of the system and cumulative kWh's generated by the system in 20 years lifetime.

\begin{tabular}{ccccc}
\hline Year & $\begin{array}{c}\text { Cost per Year (\$) } \\
\text { (Capital + Running) }\end{array}$ & $\begin{array}{c}\text { Cumulative Cost } \\
\text { for 20 Years (\$) }\end{array}$ & $\begin{array}{c}\text { kWh's Generated per } \\
\text { Year with 5\% Decrease } \\
\text { per Year after the 3rd Year }\end{array}$ & $\begin{array}{c}\text { Cumulative kWh's } \\
\text { Generated in 20 Years }\end{array}$ \\
\hline 0 & 627 & 627.00 & 0 & 0 \\
1 & 8.55 & 635.55 & 888.26 & 888.26 \\
2 & 8.55 & 644.10 & 888.26 & 1776.53 \\
3 & 8.55 & 652.65 & 888.26 & 2664.79 \\
4 & 53.58 & 706.23 & 843.85 & 3508.64 \\
5 & 8.55 & 714.78 & 801.65 & 4310.29 \\
6 & 8.55 & 723.33 & 761.57 & 5071.87 \\
7 & 55.67 & 779.00 & 723.49 & 5795.37 \\
8 & 8.55 & 787.55 & 687.32 & 6482.69 \\
9 & 8.55 & 796.10 & 652.96 & 7135.64 \\
10 & 57.95 & 654.05 & 620.31 & 8345.95 \\
11 & 8.55 & 862.60 & 589.29 & 8905.07 \\
12 & 8.55 & 571.15 & 559.83 & 9436.91 \\
13 & 59.85 & 931.00 & 531.84 & 9942.15 \\
14 & 8.55 & 939.55 & 505.24 & $10,422.13$ \\
15 & 8.55 & 948.10 & 479.98 & $10,878.11$ \\
16 & 62.7 & 1010.80 & 455.98 & $11,311.29$ \\
17 & 8.55 & 1019.35 & 433.18 & $11,722.82$ \\
18 & 8.55 & 1027.90 & 411.52 & $12,113.77$ \\
19 & 65.55 & 1093.45 & 390.95 & $12,485.17$ \\
20 & 8.55 & 1102.00 & 371.40 & - \\
\hline- & 1102 & - & $\mathbf{1 2 , 4 8 5 . 1 7}$ & \\
\hline
\end{tabular}


Thus, the calculated per unit cost of the hybrid DCMG system from Equation (1) is $\$ 0.0883$ (i.e., PKR 9.3/-). Likewise, if this system works in grid-tied mode with power utility company, at the average per unit cost (i.e., PKR 15/- $=\$ 0.1425$ per unit) charged by the company to their residential customers, the payback period (PBP) with uneven cash flow of the proposed system has been analyzed by using the Equation (3);

$$
\text { Payback Period }=A+\frac{B}{C}
$$

where, $A=$ the years before full recovery; $B=$ the uncovered cost at the start of the year, and $C=$ the cash flow during the year.

PBP is an easiest and most common method to check the economic worth of any project. Its calculation will determine the minimum number of years with positive cash flow required to exceed the invested capital cost [52]. By deducing the annual cost of investment from the annual gross revenue, the net cash flow can be calculated. PBP of any project must be less than the useful lifetime of that project. Thus, it is a deciding factor to finalize whether to work on a project or not [53].

Table 6 presents the cumulative cost, cumulative generated revenue and cumulative cash flow of the hybrid DCMG system. The cumulative benefit of the system is calculated by multiplying per unit cost to the cumulative kWh's generated by the system. Cash flow is earned and spent stream of the money that can be the money earned is the inflow and the money spent is the outflow. A positive cash flow shows that the earned money is more than the spent money. A project with greater positive cash flow shows more profit for any company.

Subsequently, the cash flow of the designed system is shown in Figure 15. Moreover, from Table 6 the values of the interest are found to be $A=6, B=-1$ and $C=47$.

$$
\text { Payback Period }=A+\frac{|B|}{C}=6+\frac{|-1|}{47}=6.02 \approx 6 \text { Years }
$$

Hence the calculated PBP of the designed system is 6 years, showing that after 6 years the designed system will generate a positive cash flow, i.e., it will be profitable for its stakeholders and continue this trend for remaining 14 years of its lifetime.

This fact is also illustrated in Figures 15 and 16. The bar below the reference line at the very first stage of Figure 15 shows the capital cost (equipment purchase and installation cost) of the system as a negative cash flow, i.e., cash outflow. The real bars ahead depict the cash inflows, i.e., positive cash flows generated by the system with time. After every three years, a considerable decrease in positive cash flows can be observed from the figure. These are because of the replacement cost of the battery which is expected to be replaced after every three years. As the performance of the battery depends on the variety of the factors and temperature is one of the critical factors which influences the performance of the battery.

As the region of concern remains very hot during the major part of the year, keeping in view, the economic analysis of the designed system is carried out with this battery replacement scheduled. It must be noted that all these calculations are done by taking into consideration the fixed value of per unit cost for the entire 20 years period of the designed system and no any depreciation factor is counted.

The cumulative cash flow has been depicted in Figure 16, that apparently predicts the payback period of the designed DCMG system is 6 years only if the generated electrical energy from DCMG system is sold to its consumers at the rate of $\$ 0.1425$ per unit (i.e., PKR 15/-). Thus, for the 14 years, the designed system will earn a profit for its stakeholders if the project's life is considered to be of 20 years. 
Table 6. The Cumulative Cost, Cumulative Generated Revenue and Cumulative Cash Flow of the Hybrid DCMG System.

\begin{tabular}{|c|c|c|c|c|c|c|c|}
\hline Year & $\begin{array}{l}\text { Cost per } \\
\text { Year (\$) (1) }\end{array}$ & $\begin{array}{l}\text { Cumulative Cost } \\
\text { (for } 20 \text { Years) (\$) (2) }\end{array}$ & $\begin{array}{l}\text { Cumulative kWh's } \\
\text { Generated (3) }\end{array}$ & $\begin{array}{c}\text { Generated Revenue } \\
\text { (at } 0.1425 / \text { Unit) (\$) (4) }\end{array}$ & $\begin{array}{c}\text { Cumulative Generated } \\
\text { Revenue (\$) (5) }\end{array}$ & $\begin{array}{l}\text { Cash Flow (\$) } \\
(6)=(4)-(1)\end{array}$ & $\begin{array}{c}\text { Cumulative } \\
\text { Cash Flow (\$) (6) }\end{array}$ \\
\hline 0 & 627.00 & 627.00 & 0.00 & 0.00 & 0.00 & -627.00 & -627.00 \\
\hline 1 & 8.55 & 635.55 & 888.26 & 126.58 & 126.58 & 118.03 & -508.97 \\
\hline 2 & 8.55 & 644.10 & 1776.53 & 126.58 & 253.16 & 118.03 & -390.94 \\
\hline 3 & 8.55 & 652.65 & 2664.79 & 126.58 & 379.73 & 118.03 & -272.92 \\
\hline 4 & 53.58 & 706.23 & 3508.64 & 120.25 & 499.98 & 66.67 & -206.25 \\
\hline 5 & 8.55 & 714.78 & 4310.29 & 114.24 & 614.22 & 105.69 & -100.56 \\
\hline $6(\mathrm{~A})$ & 8.55 & 723.33 & 5071.87 & 108.52 & 722.74 & 99.97 & $-0.59(\mathrm{~B})$ \\
\hline 8 & 8.55 & 787.55 & 6482.69 & 97.94 & 923.78 & 89.39 & 136.23 \\
\hline 9 & 8.55 & 796.10 & 7135.64 & 93.05 & 1016.83 & 84.50 & 220.73 \\
\hline 10 & 57.95 & 854.05 & 7755.95 & 88.39 & 1105.22 & 30.44 & 251.17 \\
\hline 11 & 8.55 & 862.60 & 8345.24 & 83.97 & 1189.20 & 75.42 & 326.60 \\
\hline 12 & 8.55 & 871.15 & 8905.07 & 79.78 & 1268.97 & 71.23 & 397.82 \\
\hline 13 & 59.85 & 931.00 & 9436.91 & 75.79 & 1344.76 & 15.94 & 413.76 \\
\hline 14 & 8.55 & 939.55 & 9942.15 & 72.00 & 1416.76 & 63.45 & 477.21 \\
\hline 15 & 8.55 & 948.10 & $10,422.13$ & 68.40 & 1485.15 & 59.85 & 537.05 \\
\hline 16 & 62.7 & 1010.80 & $10,878.12$ & 64.98 & 1550.13 & 2.28 & 539.33 \\
\hline 18 & 8.55 & 1027.90 & $11,722.82$ & 58.64 & 1670.50 & 50.09 & 642.60 \\
\hline 19 & 65.55 & 1093.45 & $12,113.77$ & 55.71 & 1726.21 & -9.84 & 632.76 \\
\hline 20 & 8.55 & 1102.00 & $12,485.17$ & 52.92 & 1779.14 & 44.37 & 677.14 \\
\hline- & 1102.00 & - & - & 1779.14 & - & 677.14 & - \\
\hline
\end{tabular}




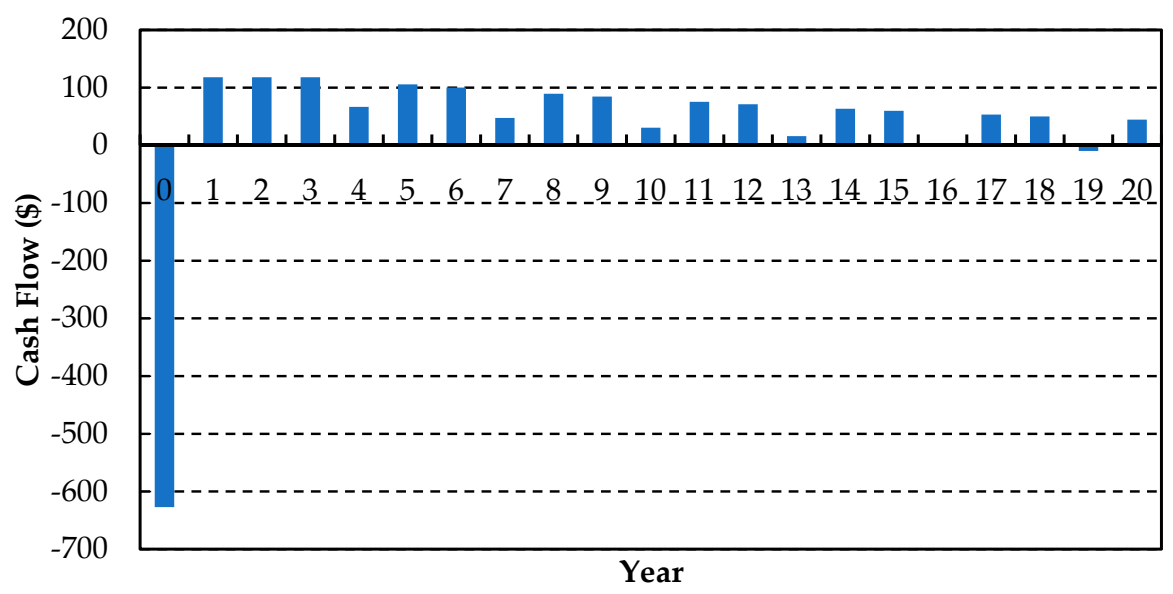

Figure 15. The cash flow analysis of the hybrid DCMG system for 20-year lifetime.

In order to analyze more precisely the economic feasibility of the designed DCMG system, the discounted payback period (DPBP) is also examined. As PBP ignores the time value of money, hence DPBP overcome this major drawback of PBP. By discounting the cash flows of the project, the DPBP accounts for the time value of money [52]. Equation (4) is the mathematical relationship to calculate the DPBP. For the equal amount of generated energy sell at the same per unit cost of $\$ 0.1425$, the discounted cumulative cost, discounted cumulative generated revenue and the discounted cumulative cash flow at the discount rate of $7 \%$ are presented in Table 7 . The $7 \%$ discount rate is selected as per the present standard rate of State Bank of Pakistan (SBP) [54]:

$$
\text { Discounted Payback Period }=A+\frac{B}{C}
$$

where, $A=$ Last period with a negative discounted cumulative cash flow; $B=$ Absolute value of discounted cumulative cash flow at the end of the period $A ; C=$ Discounted cash flow during the period after $A$.

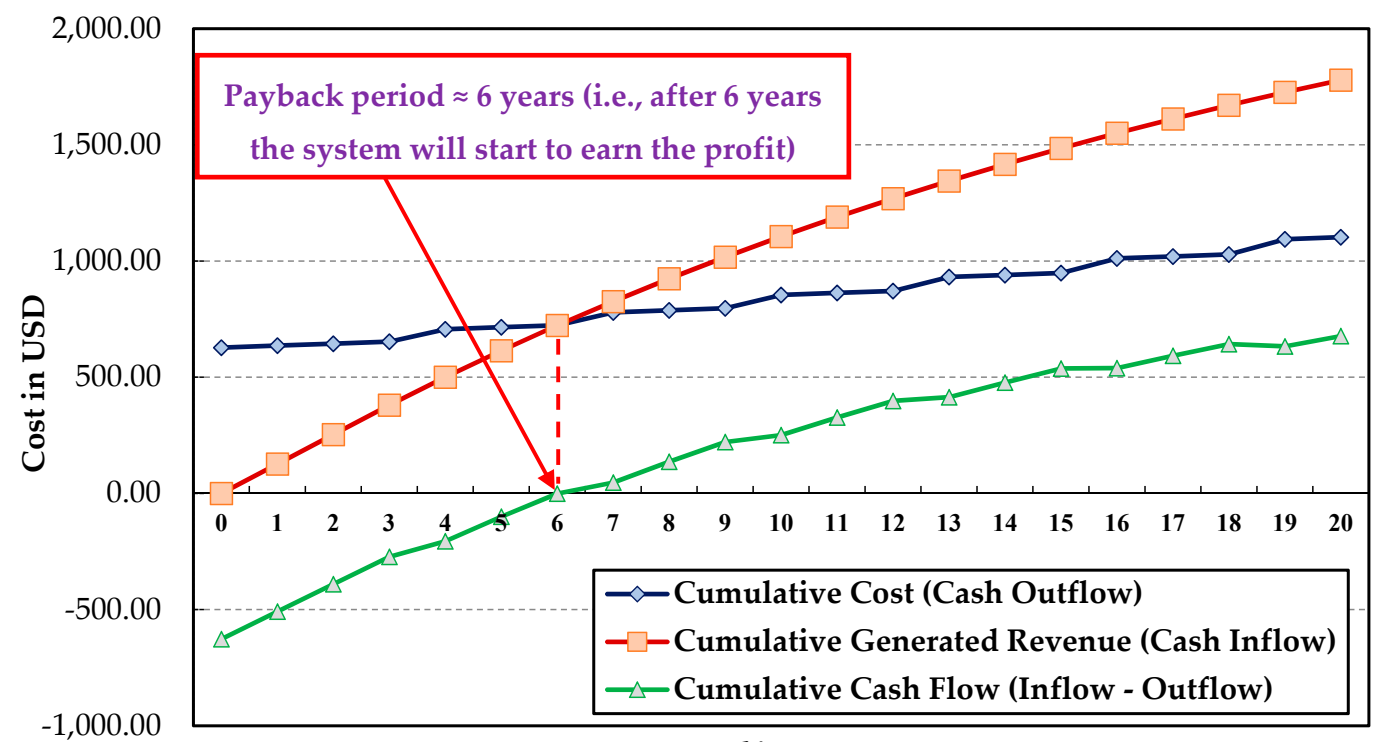

\section{Years}

Figure 16. The cumulative cash flow and payback period analysis of the hybrid DCMG system for a 20-year lifetime. 
Table 7. The discounted cumulative cost, discounted cumulative generated revenue and the discounted cumulative cash flow of the hybrid DCMG system.

\begin{tabular}{|c|c|c|c|c|c|c|c|}
\hline Year & $\begin{array}{l}\text { Discounted Cost } \\
\text { per Year (\$) (1) }\end{array}$ & $\begin{array}{l}\text { Discounted Cumulative } \\
\text { Cost (for } 20 \text { Years) (\$) (2) }\end{array}$ & $\begin{array}{l}\text { Cumulative kWh's } \\
\text { Generated (3) }\end{array}$ & $\begin{array}{c}\text { Discounted Generated } \\
\text { Revenue (at } \\
0.1425 / \text { unit) (\$) (4) }\end{array}$ & $\begin{array}{c}\text { Discounted Cumulative } \\
\text { Generated Revenue (\$) (5) }\end{array}$ & $\begin{array}{l}\text { Discounted } \\
\text { Cash Flow (\$) } \\
(6)=(4)-(1)\end{array}$ & $\begin{array}{l}\text { Discounted } \\
\text { Cumulative Cash } \\
\text { Flow (\$) (7) }\end{array}$ \\
\hline 0 & 627.00 & 627.00 & 0.00 & 0.00 & 0.00 & -627.00 & -627.00 \\
\hline 1 & 7.99 & 634.99 & 888.26 & 118.30 & 118.30 & 110.31 & -516.69 \\
\hline 2 & 7.47 & 642.46 & 1776.53 & 110.56 & 228.86 & 103.09 & -413.60 \\
\hline 3 & 6.98 & 649.44 & 2664.79 & 103.33 & 332.19 & 96.35 & -317.25 \\
\hline 4 & 40.88 & 690.31 & 3508.64 & 91.74 & 423.92 & 50.86 & -266.39 \\
\hline 5 & 6.10 & 696.41 & 4310.29 & 81.45 & 505.38 & 75.36 & -191.03 \\
\hline 6 & 5.70 & 702.11 & 5071.87 & 72.31 & 577.69 & 66.61 & -124.42 \\
\hline 7 & 34.67 & 736.78 & 5795.37 & 64.21 & 641.89 & 29.54 & -94.88 \\
\hline $8(\mathrm{~A})$ & 4.98 & 741.75 & 6482.69 & 57.00 & 698.89 & 52.03 & -42.86 (B) \\
\hline 9 & 4.65 & 746.40 & 7135.64 & 50.61 & 749.51 & $45.96(\mathrm{C})$ & 3.11 \\
\hline 10 & 29.46 & 775.86 & 7755.95 & 44.93 & 794.44 & 15.47 & 18.58 \\
\hline 11 & 4.06 & 779.92 & 8345.24 & 39.89 & 834.33 & 35.83 & 54.41 \\
\hline 12 & 3.80 & 783.72 & 8905.07 & 35.42 & 869.76 & 31.63 & 86.04 \\
\hline 13 & 24.84 & 808.56 & 9436.91 & 31.45 & 901.21 & 6.61 & 92.65 \\
\hline 14 & 3.32 & 811.87 & 9942.15 & 27.92 & 929.13 & 24.61 & 117.26 \\
\hline 15 & 3.10 & 814.97 & $10,422.13$ & 24.79 & 953.92 & 21.69 & 138.95 \\
\hline 16 & 21.24 & 836.21 & $10,878.12$ & 22.01 & 975.93 & 0.77 & 139.72 \\
\hline 17 & 2.71 & 838.92 & $11,311.29$ & 19.54 & 995.47 & 16.84 & 156.56 \\
\hline 18 & 2.53 & 841.44 & $11,722.82$ & 17.35 & 1012.82 & 14.82 & 171.38 \\
\hline 19 & 18.13 & 859.57 & $12,113.77$ & 15.40 & 1028.23 & -2.72 & 168.66 \\
\hline 20 & 2.21 & 861.78 & $12,485.17$ & 13.68 & 1041.90 & 11.47 & 180.12 \\
\hline- & 861.78 & - & - & 1041.90 & - & 180.12 & - \\
\hline
\end{tabular}


From Table 7 the values of the interest are found to be $A=8, B=-42.86$, and $C=45.96$ :

$$
\text { Discounted Payback Period }=A+\frac{|B|}{C}=8+\frac{|-42.86|}{445.96}=8.96 \approx 9 \text { Years }
$$

Thus, with a discount rate of $7 \%$ for the designed system with a useful lifetime of 20 years, the calculated DPBP is 9 years, shown in Figure 17. Comparably, this is an acceptable value of DPBP as it is much less than the useful lifetime of the project and has the substantial margin to earn a profit for the stakeholders.

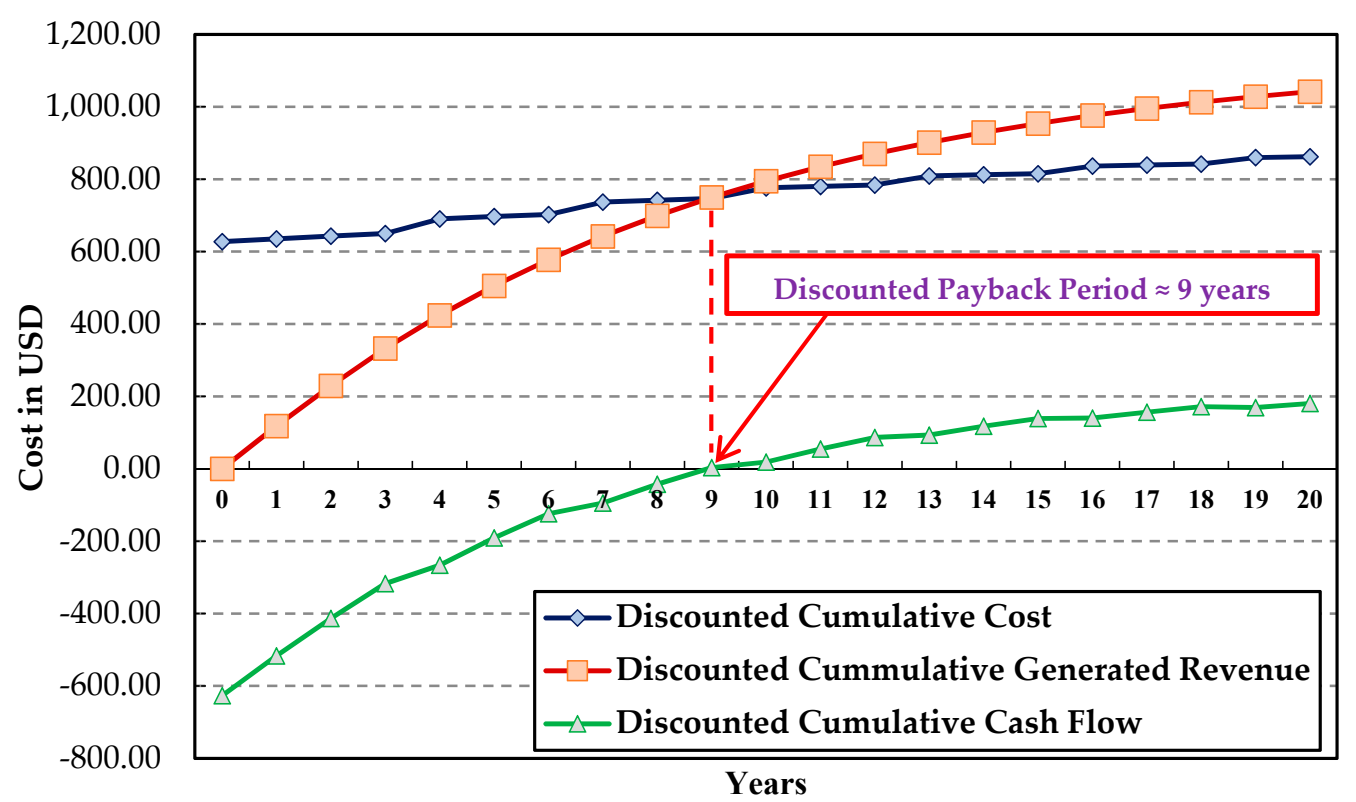

Figure 17. The discounted cumulative cash flow and discounted payback period analysis of the hybrid DCMG system for a 20-year lifetime.

The generator specifications are listed in Table 8. Similar to WG system, any major repair work of gasoline generator is also ignored in the entire lifetime. An amount of $5 \%$ of equipment cost is added for the regular repair and maintenance work per annum. It is a well-known fact that a significant part of the running cost of any gasoline generator is its fuel requirement throughout its life period. Before calculating the fuel cost of the specified gasoline generator over the 20-year lifetime in a similar pattern as of the hybrid DCMG system, it is assumed that total kWh generated by this gasoline generator will be reduced by $5 \%$ per year after first three years of use. As such, the consumption of fuel is calculated by using the Equation (5):

$$
C=E \times C k W h(\text { in litres) }
$$

where $E$ is the active electrical energy in output $(\mathrm{kWh})$, and $C \mathrm{kWh}$ is the consumption of fuel per $\mathrm{kWh}$. The term $E$ is calculated by using the Equation (6):

$$
E=P \times h \times d(\text { in } \mathrm{kWh})
$$

where $P$ is the active electrical energy in output $(\mathrm{kW}), h$ is the number of hours per day the generator operates, and $d$ is the number of days the generator runs. 
Table 8. Gasoline generator specifications.

\begin{tabular}{cc}
\hline Parameter & Characteristics \\
\hline Max. AC output & $550 \mathrm{VA}$ \\
Rated AC output & $450 \mathrm{VA}$ \\
DC output & $12 \mathrm{~V} * 8.3 \mathrm{~A}$ \\
Type & Single cylinder, 4 stroke \\
Petrol consumption & $0.49 \mathrm{~L}$ in $1 \mathrm{~h}$ \\
Price & $51,000 /-\mathrm{PKR}$ \\
\hline
\end{tabular}

On the basis of average per hour generation of $0.153 \mathrm{kWh}$, the generator running time is $17 \mathrm{~h} /$ day in summer and $13 \mathrm{~h} /$ day in winter, as such, the status of the total cost of the generator system is given in Table 9. Whereas the detail pertaining to total $\mathrm{kWh}$ generated per year, fuel consumption per year and its cost is presented in Table 10.

Table 9. The capital and running costs of the generator system of equal capacity.

\begin{tabular}{|c|c|c|c|c|}
\hline \multirow[b]{2}{*}{ Equipment } & \multirow{2}{*}{$\begin{array}{c}\text { Capital } \\
\text { (Equipment) Cost }\end{array}$} & \multicolumn{2}{|c|}{ Running Cost } & \multirow[b]{2}{*}{ Total Cost } \\
\hline & & $\begin{array}{c}\text { Repair and } \\
\text { Maintenance Cost }\end{array}$ & Fuel Cost & \\
\hline $\begin{array}{c}\text { Gasoline } \\
\text { Generator set }\end{array}$ & $\begin{array}{c}51,000 /-P K R \\
(\$ 484)\end{array}$ & $\begin{array}{c}2550 \times 20=51,000 / \text {-PKR } \\
(\$ 484) \\
\text { At the rate of } 5 \% \text { of the } \\
\text { equipment cost per year }\end{array}$ & $\begin{array}{c}289,441 /-\mathrm{PKR} \\
(\$ 2750) \\
\text { At price of } \$ 0.7 \text { per liter }\end{array}$ & $\begin{array}{c}391,441 /-\mathrm{PKR} \\
(\$ 3718)\end{array}$ \\
\hline
\end{tabular}

Table 10. kWhs generated, fuel consumption, fuel cost and total cost scenario of the generator set for 20 years lifetime.

\begin{tabular}{ccccc}
\hline Year & Cost per Year $\mathbf{( \$ )}$ & $\begin{array}{c}\text { kWh's Generated with } \\
\mathbf{5} \text { o Decrease per Year } \\
\text { after the 3rd Year }\end{array}$ & $\begin{array}{c}\text { Litres Consumed } \\
\text { per Year }\end{array}$ & $\begin{array}{c}\text { Fuel Cost Price of } \\
\mathbf{\$ 0 . 7} \text { per Litre }\end{array}$ \\
\hline 0 & 485 & 0 & 0 & 0 \\
1 & 220 & 888.26 & 282.09 & 195.77 \\
2 & 220 & 888.26 & 282.08 & 195.76 \\
3 & 220 & 888.26 & 282.09 & 195.77 \\
4 & 210 & 843.85 & 267.98 & 185.98 \\
5 & 201 & 801.66 & 254.58 & 176.68 \\
6 & 192 & 761.57 & 241.85 & 167.85 \\
7 & 184 & 723.49 & 229.76 & 159.45 \\
8 & 176 & 687.32 & 218.27 & 151.48 \\
9 & 168 & 652.96 & 207.36 & 143.91 \\
10 & 161 & 620.31 & 196.99 & 136.71 \\
11 & 154 & 589.29 & 187.14 & 129.88 \\
12 & 148 & 559.83 & 177.79 & 117.21 \\
13 & 141 & 531.84 & 168.89 & 111.35 \\
14 & 135 & 505.24 & 160.45 & 105.79 \\
15 & 130 & 479.98 & 152.43 & 100.49 \\
16 & 125 & 455.98 & 144.81 & 95.47 \\
17 & 120 & 433.18 & 137.57 & 90.69 \\
18 & 115 & 411.52 & 130.69 & 86.16 \\
19 & 110 & 390.95 & 124.15 & 81.85 \\
20 & 106 & 371.40 & 117.95 & 2751.67 \\
\hline- & 3718 & $12,485.17$ & 3964.94 & \\
\hline
\end{tabular}

The percentage shares of capital and running costs in the total cost of the generator system for the entire 20 years' lifetime is shown in Figure 18. The generator's running cost is further divided into fuel 
cost and operation \& maintenance costs; moreover, the percentage shares in the total running cost are given in Figure 19. From Equation (2), the computed per unit cost of the gasoline generator system is $\$ 0.3$ (i.e., 31.4/-PKR), which is about 3.4 times greater than the per unit cost of the hybrid DCMG system. Thus, if this generator set operates in grid-tied mode, then it will continuously operate with negative cash flow in its lifetime at the rate of $\$ 0.1425$ per unit, which is the minimum cost of the unit charged by power generation companies from their residential consumers.

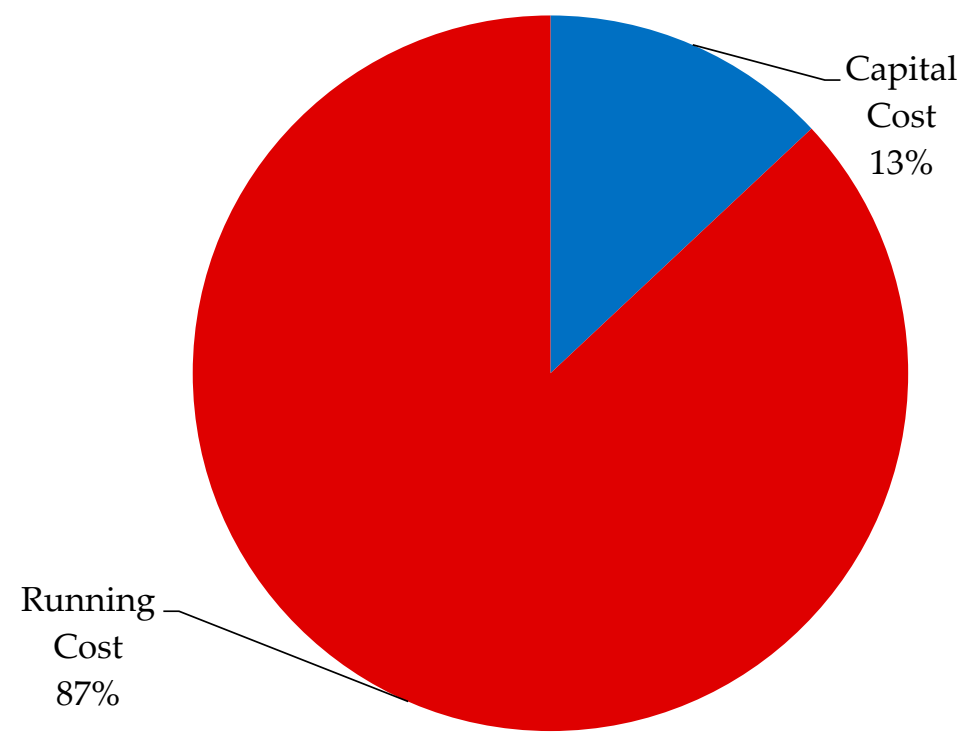

Figure 18. The percentage share of capital and running costs in the total cost of the generator system for a 20-year lifetime.

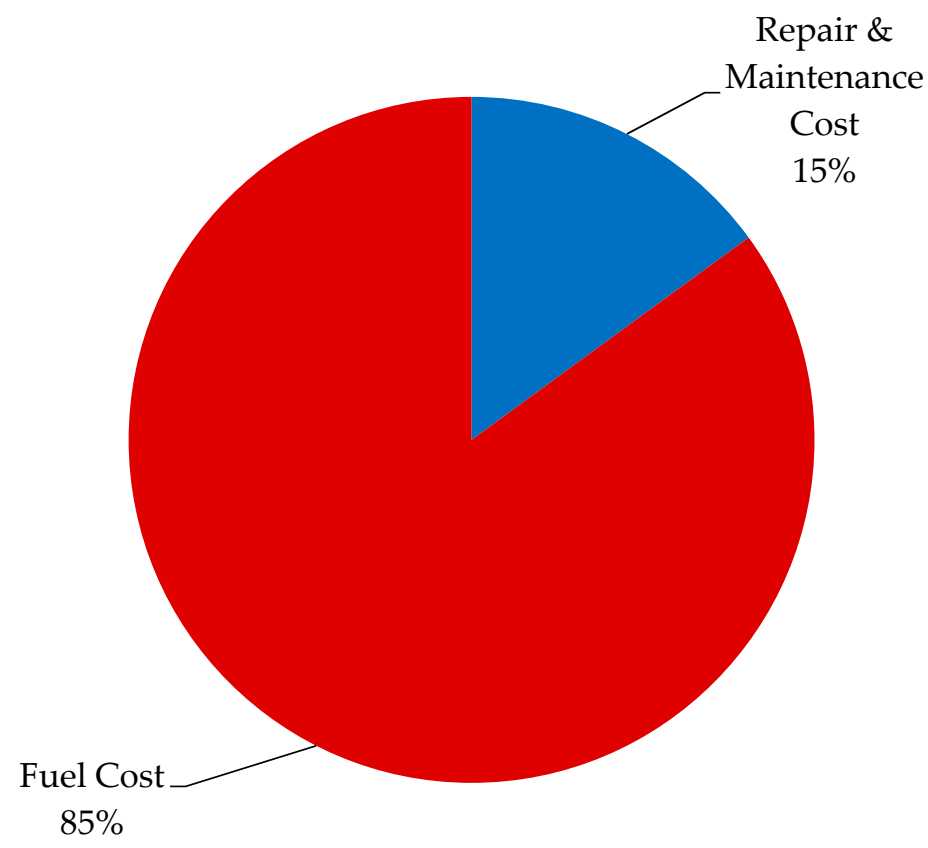

Figure 19. The percentage share of repair \& maintenance cost and fuel cost in the total running cost of the generator system for a 20-year lifetime.

Figure 20 gives a cost comparison between the designed DCMG and the traditional gasoline generator. The cost comparison graph is divided into three sections, i.e., capital cost, running cost and the total (lifetime) cost of the two systems. The key finding of the proposed work is that for the 
long-term use, the HRE DCMG system is a most suitable option for the stakeholders. The following points summarize the cost comparison between two systems:

Capital cost of the DCMG system $=1.295$ times to the capital cost Gasoline Generator Running cost of the DCMG system $=0.147$ times to that of the Gasoline Generator Total (lifetime) cost of the DCMG system $=0.296$ times to that of the Gasoline Generator

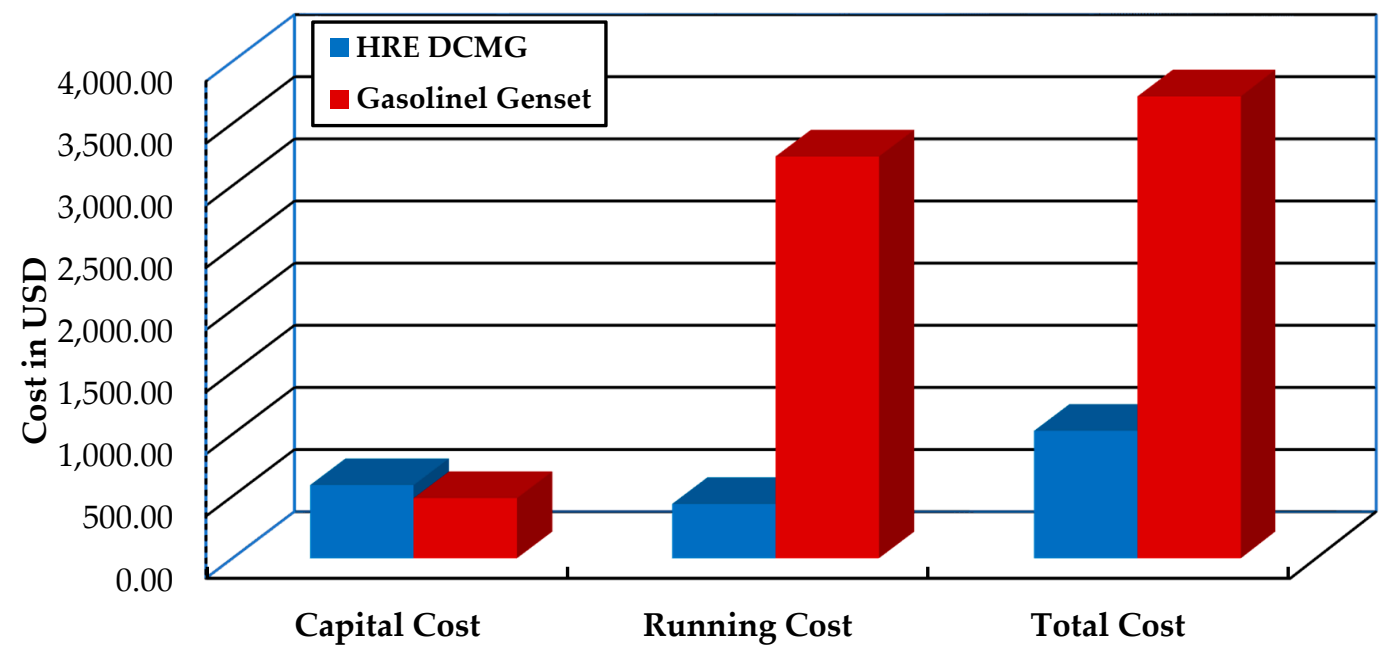

Figure 20. The cost comparison of hybrid renewable energy-based DC microgrid (HRE DCMG) and the gasoline generator set.

The total lifetime cost comparison between two systems provides a clear picture of the economic benefit of the designed DCMG system. The hybrid DCMG system has a high capital cost but the lifetime cost of the designed system absolutely overshadows this drawback. Hence, a small hybrid DCMG system of only $0.5 \mathrm{~kW}$ capacity can save up to $70 \%$ of the lifetime cost of the gasoline generator system which is equal to $\$ 2600$ in the present case. This motivates the adaptation of the designed system on the larger scale. The details of the cost comparison have been computed in Table 11. The capital cost of a hybrid DCMG system is $29.5 \%$ higher than that of a gasoline generator. The running cost of the hybrid DCMG system is $85.3 \%$ less than that of the gasoline generator and the lifetime cost of the hybrid DCMG system is $70.4 \%$ less than that of the gasoline generator.

Table 11. The cost comparison of the hybrid DCMG and gasoline generator systems.

\begin{tabular}{cccc}
\hline Sr. \# & Cost Comparison & Hybrid DCMG (\$) & Gasoline Generator (\$) \\
\hline 1 & Capital Cost & 627 & 484 \\
2 & Running Cost & 475 & 3234 \\
3 & Total (Lifetime) Cost & 1102 & 3718 \\
\hline
\end{tabular}

The per year cost comparison of the two systems is depicted in Figure 21. It presents the details of the cost comparison given in Figure 20. The zero point on the horizontal axis of Figure 21 provides the capital cost comparison between the two systems, while the remaining 20 points compare the running cost of the two systems. The running cost of the hybrid DCMG system is based on the maintenance and replacement costs of the system components, whereas, the running cost of the gasoline generator system comprises the maintenance and components replacement cost plus the cost of the fuel. The running cost of the gasoline generator are found greater than the running cost of the hybrid DCMG system except for the years when the battery of hybrid DCMG system will be replaced because of their limited lifecycle. 


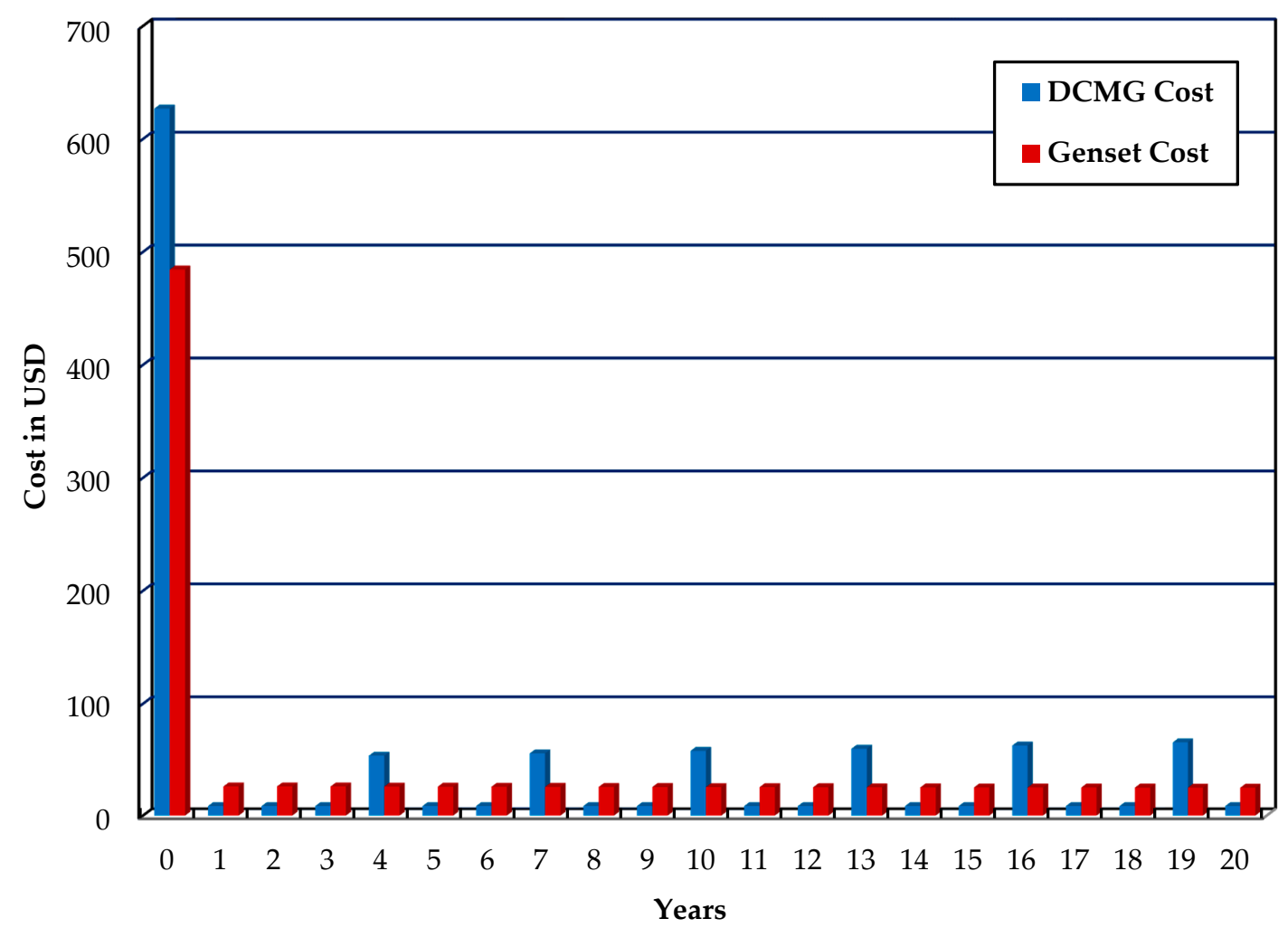

Figure 21. Per year cost comparison between HRE DCMG and the gasoline generator systems.

\section{Conclusions}

The hybrid DCMG system studied in this paper has great potential to replace gasoline generators of the same size. Although, the DCMG system distributed generator resources, i.e., wind and solar, are not consistent yet adding a storage battery delivers optimal results. The comparative analysis of the hybrid DCMG system with a gasoline generator system of equal capacity indicates that the hybrid DCMG system has the wide potential to supply cost effective electrical energy. This is despite the fact that the capital cost of a hybrid DCMG system is $29.5 \%$ higher than that of the gasoline generator. However, the running cost of the hybrid DCMG system has been determined to be $85.3 \%$ less than that of the gasoline generator and the lifetime costs of the hybrid DCMG system are also $70.4 \%$ less than those of the gasoline generator. It is therefore established that adopting the proposed hybrid DCMG system will bring substantial cost savings of approximately $\$ 0.2117$ in the per unit prices in terms of electricity generation cost and the hybrid DCMG hence has sufficient potential and prospects to replace conventional gasoline generators for remote off-grid areas or for various backup power applications Finally and most importantly, the hybrid DCMG system is a pollution-free production of electrical energy system which adds to the various other advantages of the system.

Author Contributions: All authors contributed for bringing the manuscript in its current state. P.H.S., Z.H.L. and A.R.S. have conceived the idea, design the experimental setup and analyzed the data. N.H.M and F.S. have supported in arrangement, analysis and type setting of the manuscript. T.J. and M.A.U have edited and proofread the manuscript. The authors are acknowledged for their contributions including study design, detailed survey of the literature, development of the experimental setup, and results \& analyses for the completion of this study.

Acknowledgments: The authors are grateful to the United States Pakistan Centre for Advanced Studies in Energy (USPCAS-E) Peshawar for project grant (USPCAS-E ARG-Dec15-042) to carry out the research. They would also like to acknowledge Mehran University of Engineering and Technology (MUET) Jamshoro \& University of Engineering and Technology (UET) Peshawar for jointly carrying the project.

Conflicts of Interest: The authors declare no conflicts of interest. 


\section{References}

1. Nfah, E.M.; Ngundam, J.M.; Tchind, R. Modelling of solar/diesel/battery hybrid power systems for far-north Cameroon. Renew. Energy 2007, 32, 832-844. [CrossRef]

2. The Global Wind Energy Council. Global Wind Energy Outlook; The Global Wind Energy Council: Brussels, Belgium, 2016.

3. Lins, C.; Williamson, L.E.; Leitner, S.; Teske, S. The First Decade: 2004-2014, 10 Years of Renewable Energy Progress; Renewable Energy Policy Network of 21st Century (REN21): Paris, France, 2014.

4. Shaikh, P.H.; Shaikh, F.; Mirani, M. Solar Energy: Topographical Asset for Pakistan. Appl. Sol. Energy 2013, 48, 49-53. [CrossRef]

5. Alternative Energy Development Board. Rural Electrification Program. 2014. Available online: http: //www.aedb.org/ (accessed on 11 April 2015).

6. Barley, C.D. Optimal dispatch strategy in remote hybrid power systems. Sol. Energy 1996, 58, 165-179. [CrossRef]

7. Ghafoor, A.; Rehman, T.; Munir, A.; Ahmad, M.; Iqbal, M. Current status and overview of renewable energy potential in Pakistan for continuous energy sustainability. Renew. Sustain. Energy Rev. 2016, 60, 1332-1342. [CrossRef]

8. Uddin, W.; Khan, B.; Shaukat, N.; Majid, M.; Mujtaba, G.; Mehmood, A.; Ali, S.M.; Younas, U.; Anwar, M.; Almeshal, A.M. Biogas potential for electric power generation in Pakistan: A survey. Renew. Sustain. Energy Rev. 2016, 54, 25-33. [CrossRef]

9. Notton, G.; Muselli, M.; Louche, A. Autonomous hybrid photovoltaic power plant using a back-up generator: A case study in a Mediterranean Island. Renew. Energy 1996, 7, 371-391. [CrossRef]

10. Ulfat, I.; Javed, F.; Abbasi, F.A.; Kanwal, F.; Usman, A.; Jahangir, M.; Ahmad, F. Estimation of solar energy potential for Islamabad, Pakistan. Energy Procedia 2012, 18, 1496-1500. [CrossRef]

11. Bhutto, A.W.; Aqeel, A.B.; Gholamreza, Z. Greener energy: Issues and challenges for Pakistan-Solar energy prospective. Renew. Sustain. Energy Rev. 2012, 16, 2762-2780. [CrossRef]

12. Luqman, M.; Sajid, R.A.; Samiullah, K.; Usman, A.; Ahmad, R.; Farkhanda, A. Estimation of solar energy potential from the roof top of Punjab Government Servants Cooperative Housing Society Lahore using GIS. Smart Grid Renew. Energy 2015, 6, 128-139. [CrossRef]

13. The National Renewable Energy Laboratory (NREL). Pakistan Resource Maps and Toolkit; The National Renewable Energy Laboratory (NREL): Golden, CO, USA, 2014.

14. Farooqui, S.Z. Prospects of renewable penetration in the energy mix of Pakistan. Renew. Sustain. Energy Rev. 2014, 29, 693-700. [CrossRef]

15. Khan, N.A. Energy Resources and Utilization in Pakistan; College of EME: Rawalpindi, Pakistan, 2000.

16. Nayyer, A.Z.; Nayyer, Z.A. Prospects of renewable energy resources in Pakistan. In Renewable-Energy Technologies and Sustainable Development; Comsats: Islamabad, Pakistan, February 2005; pp. 65-86.

17. Manoj, S.; Srinivasaiah, P.P. Estimation and Cost Effective Analysis of Hybrid-Wind/PV Generation for Rural/Remote Electrification. Int. J. Emerg. Technol. Adv. Eng. 2012, 2, 740-745.

18. Abbas, M.K.; Hassan, Q. Economic Power Generation for an off-Grid site in Pakistan. In Proceedings of the IEEE 2015 Power Generation System and Renewable Energy Technologies (PGSRET), Islamabad, Pakistan, 10-11 June 2015.

19. Maouedj, R.; Mammeri, A.; Benyoucef, B. Performance evaluation of hybrid Photovoltaic-Wind power systems. Energy Procedia 2014, 50, 797-807. [CrossRef]

20. Caisheng, W. Modeling and Control of Hybrid Wind/Photovoltaic/Fuel Cell Distributed Generation Systems. Ph.D. Thesis, Montana State University-Bozeman, College of Engineering, Bozeman, MT, USA, 2006.

21. Vivek, D.; Bhatia, J.S. Analysis and design of a domestic solar-wind hybrid energy system for low wind speeds. Int. J. Comput. Appl. 2013, 72, 40-44.

22. Sigarchian, S.G.; Anders, M.; Torsten, F. Modeling and control strategy of a hybrid PV/Wind/Engine/Battery system to provide electricity and drinkable water for remote applications. Energy Procedia 2014, 57, 1401-1410. [CrossRef]

23. Godson, J.; Karthick, M.; Muthukrishnan, T.; Sivagamasundari, M.S. Solar PV-Wind hybrid power generation System. Int. J. Adv. Res. Electr. Electron. Instrum. Eng. 2013, 11, 5350-5354. 
24. Arun, G.E.; Ashna, C.A.; Sareena, M.K.; Shijina, K. A Relay Based Controller Designing of Hybrid Power Systems. Int. J. Adv. Res. Electr. Electron. Instrum. Eng. 2015, 4, 2505-2511.

25. Wang, T. The Design of Charging Controller in Wind-Photovoltaic Hybrid Power Generation System. In Proceedings of the International Conference on Civil, Materials and Environmental Sciences (CMES 2015), London, UK, 13-14 March 2015; pp. 402-404.

26. Diab, F.; Lan, H.; Zhang, L.; Ali, S. An environmentally friendly factory in Egypt based on hybrid photovoltaic/wind/diesel/battery system. J. Clean. Prod. 2016, 112, 3884-3894. [CrossRef]

27. Freire, N.; Ribeiro, E.; Marques, A.J.; Boccaletti, C.C. Experimental Analysis of a Standalone Renewable Energy Based Hybrid System. In Proceedings of the International Conference on Computing, Electrical and Industrial Systems, Costa de Caparica, Portugal, 27-29 February 2012; Springer: Berlin/Heidelberg, Germany, 2012; pp. 337-344.

28. Muni, T.V.; Kishore, K.V. Experimental Setup of Solar-Wind Hybrid Power System Interface to Grid System. Int. J. Modern Trends Sci. Technol. 2016, 2, 1-6.

29. Jadallah, A.A.; Mahmood, D.Y.; Er, Z.; Abdulqaedr, Z.A. Hybridization of Solar/Wind Energy System for Power Generation in Rural Areas. In Proceedings of the 2nd International Conference on Computational and Experimental Science and Engineering (ICCESEN 2015), Antalya, Turkey, 14-19 October 2015; Volume 130, pp. 434-437.

30. Sungwoo, B.; Kwasinski, A. Dynamic modeling and operation strategy for a microgrid with wind and photovoltaic resources. IEEE Trans. Smart Grid 2012, 3, 1867-1876.

31. Kwasinski, A.; Krein, P.T. Optimal configuration analysis of a microgrid-based telecom power system. In Proceedings of the IEEE 28th INTELEC, Providence, RI, USA, 10-14 September 2006; pp. 1-8.

32. Kwasinski, A.; Krein, P.T. A microgrid-based telecom power system using modular multiple-input DC-DC converters. In Proceedings of the IEEE 27th INTELEC, Berlin, Germany, 18-22 September 2005; pp. 515-520.

33. Rashid, A.B.; Abusara, M.; Mallick, T. A review of hybrid solar PV and wind energy system. Smart Sci. 2015, 3, 127-138.

34. Ganesan, S.; Padmanaban, S.; Varadarajan, R.; Subramaniam, U.; Mihet-Popa, L. Study and Analysis of an Intelligent Microgrid Energy Management Solution with Distributed Energy Sources. Energies 2017, 10, 1419. [CrossRef]

35. Cucchiella, F.; D'Adamo, I.; Gastaldi, M. The Economic Feasibility of Residential Energy Storage Combined with PV Panels: The Role of Subsidies in Italy. Energies 2017, 10, 1434. [CrossRef]

36. Javaid, N.; Javaid, S.; Wadood, A.; Ahmed, I.; Almogren, A.; Alamri, A.; Niaz, I.A. A hybrid genetic wind driven heuristic optimization algorithm for demand side management in smart grid. Energies 2017, 10, 319. [CrossRef]

37. Dali, M.; Belhadj, J.; Roboam, X. Hybrid solarewind system with battery storage operating in grid-connected and standalone mode: Control and energy management-Experimental investigation. Energy 2010, 35, 2587-2595. [CrossRef]

38. Ou, T.-C.; Hong, C.-M. Dynamic operation and control of microgrid hybrid power systems. Energy 2014, 66, 314-323. [CrossRef]

39. Hong, C.-M.; Ou, T.-C.; Lu, K.-H. Development of intelligent MPPT (maximum power point tracking) control for a grid-connected hybrid power generation system. Energy 2013, 50, 270-279. [CrossRef]

40. Bui, V.-H.; Hussain, A.; Kim, H.-M. Optimal Operation of Microgrids Considering Auto-Configuration Function Using Multiagent System. Energies 2017, 10, 1484. [CrossRef]

41. Ou, T.-C.; Tsao, T.-P.; Lin, W.-M.; Hong, C.-M.; Lu, K.-H.; Tu, C.-S. A novel Power Flow Analysis for Microgrid Distribution System. In Proceedings of the 2013 8th IEEE Conference on Industrial Electronics and Applications (ICIEA), Melbourne, VIC, Australia, 19-21 June 2013.

42. Lin, W.-M.; Ou, T.-C. Unbalanced distribution network fault analysis with hybrid compensation. IET Gener. Transm. Distrib. 2011, 5, 92-100. [CrossRef]

43. Chena, S.-L.; Chen, Y.-L.; Chang, Y.-R.; Chan, C.-M. Stage Fault Test of a Low Voltage Microgrid for Development of Protection Scheme. Int. J. Smart Grid Clean Energy 2012, 1, 116-121. [CrossRef]

44. Ou, T.-C. Ground fault current analysis with a direct building algorithm for microgrid distribution. Electr. Power Energy Syst. 2013, 53, 867-875. [CrossRef]

45. Ou, T.-C. A novel unsymmetrical faults analysis for microgrid distribution systems. Electr. Power Energy Syst. 2012, 43, 1017-1024. [CrossRef] 
46. Eltamaly, A.M.; Al-Shamma'a, A.A. Optimal configuration for isolated hybrid renewable energy systems. J. Renew. Sustain. Energy 2016, 8, 045502. [CrossRef]

47. Türkay, B.E.; Telli, A.Y. Economic analysis of standalone and grid connected hybrid energy systems. Renew. Energy 2011, 36, 1931-1943. [CrossRef]

48. Shaikh, P.H.; Jan, T.; Solangi, A.R.; Leghari, Z.H.; Baloch, A.A.; Uqaili, M.A. Performance analysis of wind-photovoltaic-battery based DC microgrid setup for off-grid applications. In Proceedings of the IEEE 3rd International Conference on Engineering Technologies and Social Sciences (ICETSS), Bangkok, Thailand, 7-8 August 2017.

49. Pakistan Solar Radiation Measurement Data. Available online: https://energydata.info/dataset/pakistansolar-measurement-wbg-esmp (accessed on 31 March 2017).

50. Mulligan, C.J.; Bilen, C.; Zhou, X.; Belcher, W.J.; Dastoor, P.C. Dastoor. Levelised cost of electricity for organic photovoltaics. Sol. Energy Mater. Sol. Cells 2015, 133, 26-31. [CrossRef]

51. Gielen, D. Renewable energy technologies: Cost analysis series-Wind power. In IRENA Working Paper; Gielen, D., Ed.; International Renewable Energy Agency (IRENA): Abu Dhabi, UAE, 2012.

52. Maheshwari, H.; Jain, K. Financial Viability of Solar Photovoltaic System: A Case Study. Int. J. Civ. Eng. Technol. 2017, 8, 180-190.

53. Khambalkar, V.P.; Gadge, S.R.; Dahatonde, S.B.; Kale, M.U.; Karale, D.S. Wind Energy Cost and Feasibility of a 2 MW Wind Power Project. Int. Energy J. 2007, 8, 285-290.

54. State Bank of Pakistan. Domestic Markets and Monetary Management Department. Available online: http:/ / fma.com.pk/index.php/history-of-discount-rate/ (accessed on 24 April 2018).

(C) 2018 by the authors. Licensee MDPI, Basel, Switzerland. This article is an open access article distributed under the terms and conditions of the Creative Commons Attribution (CC BY) license (http:/ / creativecommons.org/licenses/by/4.0/). 